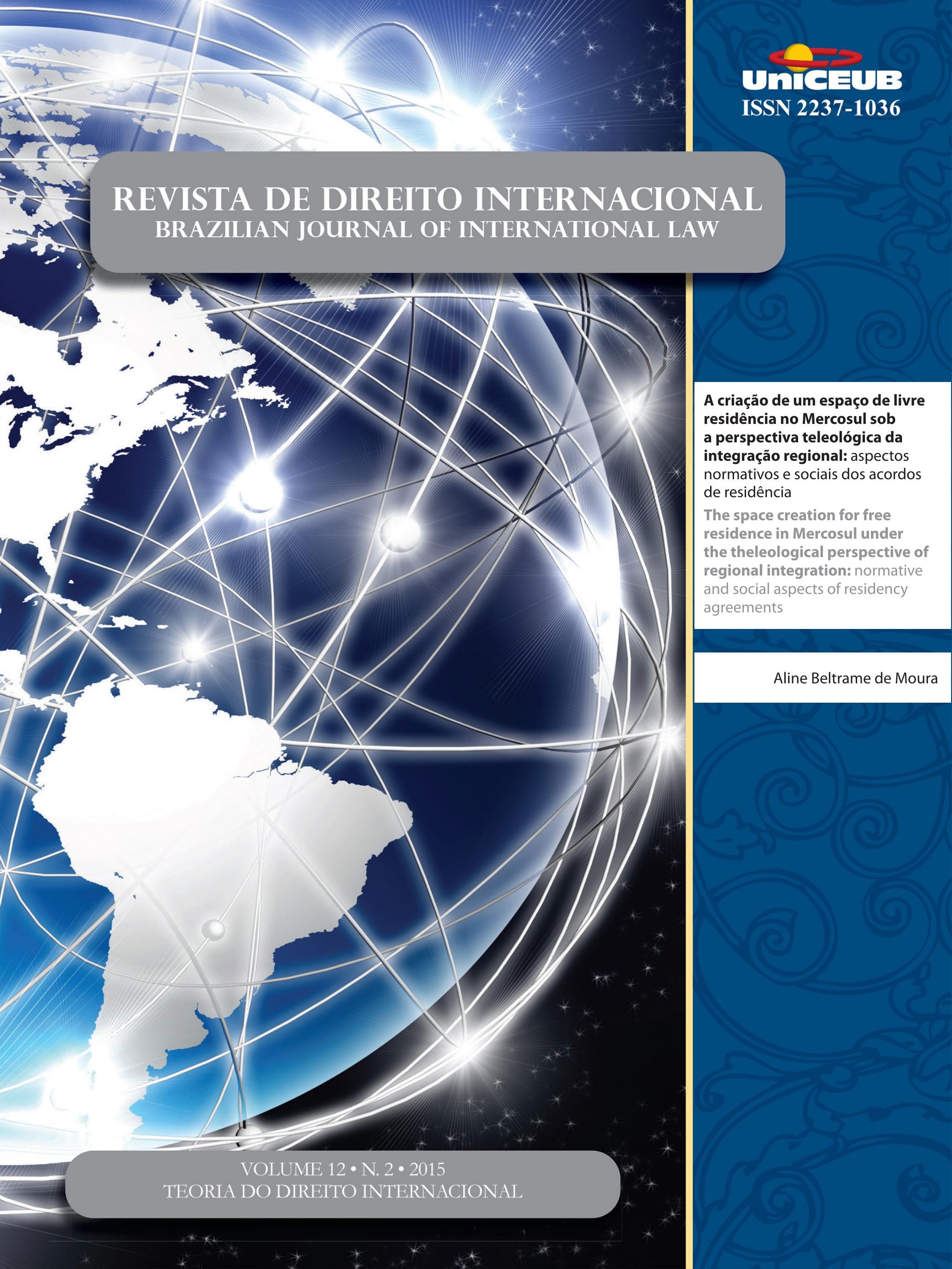




\section{Sumário}

CrôNiCAS DA ATUALIDADE do DiREITo INTERnACIONAL ..................................................... 2 Sarah Dayanna Lacerda Martins Lima, Carina Costa de Oliveira e Erika Braga

CrôniCas do Direito InternaCional dos InVESTIMENTOS ..............................................12 Nitish Monebhurrun

Por que voltar a Kelsen, o jurista do século XX ? 16 Inocêncio Mártires Coelho

O Princípio da Efetividade como conteúdo da norma fundamental (GrundNorm) DE KELSEN

Carlos Alberto Simões de Tomaz e Renata Mantovani de Lima

A JURIDIFICAÇÃo DE CONFLITOS POLÍTICOS NO DIREITO INTERNACIONAL PÚBLICO CONTEMPORÂ-

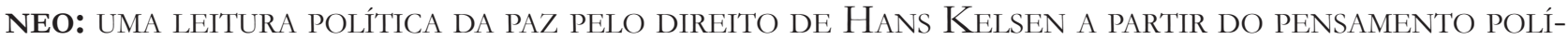
TICO De Claude Lefort

Arthur Roberto Capella Giannattasio

O SINCRETISMO TEÓRICO NA APROPRIAÇÃO DAS TEORIAS MONISTA E DUALISTA E SUA QUESTIONÁVEL UTILIDADE COMO CRITÉRIO PARA A CLASSIFICAÇÃO DO MODELO BRASILEIRO DE INCORPORA-

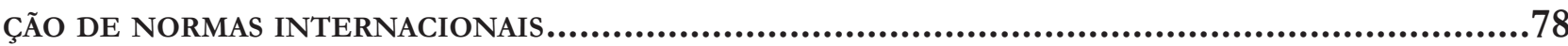
Breno Baía Magalhães

Direito Global em Pedaços: Fragmentação, Regimes e Pluralismo .98 Salem Hikmat Nasser

Por uma TeOria JURÍdica da INTEGRaÇão REgIONAL: A INTER-RELAÇÃO DiREITO INTERNO, DiREITO INTERNACIONAL PÚBLICO E DIREITO DA INTEGRAÇÃO Jamile Bergamaschine Mata Diz e Augusto Jaeger Júnior

A teOria DA INTERCONSTITUCIONALIDADE: UMA ANÁlISE COM BASE NA AMÉRICA LATINA...........160 Daniela Menengoti Ribeiro e Malu Romancini 
O DIÁLOGO HERMENÊUTICO E A PERGUNTA ADEQUADA À APLICAÇÃo DOS TRATADOS INTERNACIONAIS DE DIREITOS HUMANOS NO BRASIL: CAMINHOS PARA O PROCESSO DE INTERNACIONALIZAÇÃO

DA CONSTITUIÇÃO...................................................................................... 176

Rafael Fonseca Ferreira e Celine Barreto Anadon

O DIREITO COMPARADO NO STF: INTERNACIONALIZAÇÃO DA JURISDIÇÃO CONSTITUCIONAL BRASILEIRA

Carlos Bastide Horbach

THE PHILOSOPHY OF INTERNATIONAL LAW IN CONTEMPORARY SCHOLARSHIP: OVERCOMING NE-

GLIGENCE THROUGH THE GLOBAL EXPANSION OF HUMAN RIGHTS

Fabrício Bertini Pasquot Polido, Lucas Costa dos Anjos e Vinícius Machado Calixto

OpORTUNIDADES E DESAFIOS DAS TWAIL NO CONTEXTO LATINO-AMERICANO A PARTIR DE PERSPECTIVAS DOS POVOS INDÍGENAS AO DIREITO INTERNACIONAL

Fernanda Cristina de Oliveira Franco

Por Que uma ANÁlise ECONÔMICA Do DIREITO INTERNACIONAL PÚBLICO? DESAFIOS E PERSPECTIVAS DO MÉTODO NO BRASII

Gustavo Ferreira Ribeiro e Jose Guilherme Moreno Caiado

ANÁliSE ECONÔMICA do DIREITO INTERNACIONAL .263 Michele Alessandra Hastreiter e Luís Alexandre Carta Winter

RACIONALIDADE ECONÔMICA E OS ACORDOS BILATERAIS DE INVESTIMENTO 284 Michele Alessandra Hastreiter e Luís Alexandre Carta Winter

LOOKING FOR A BRICS PERSPECTIVE ON INTERNATIONAL LAW .304 Gabriel Webber Ziero

A INFLUÊNCIA DO DIREITO DESPORTIVO TRANSNACIONAL NO ORDENAMENTO JURÍDICO BRASILEIRO: DA REPRODUÇÃO DE NORMAS À APLICAÇÃO DIRETA PELA JURISDIÇÃO ESTATAL.......................3324 Tiago Silveira de Faria

CONVENCIONALIZAÇÃo DO DIREITO CIVIL: A APLICAÇÃo DOS TRATADOS E CONVENÇÕES INTERNACIONAIS NO ÂMBITO DAS RELAÇÕES PRIVADAS . 
NATIONAL JUdGES AND COURTS AS INSTITUTIONS FOR GLOBAL ECONOMIC GOVERNANCE 356

Juízes e tribunais nacionais como instituições para a governança global 356 Camilla Capucio

Is Trade Governance Changing? 371 Alberto do Amaral Júnior

OS FUNDOS ABUTRES: MEROS PARTICIPANTES DO CENÁRIO INTERNACIONAL OU SUJEITOS PERANTE O DIREITO INTERNACIONAL? 384

Guilherme Berger Schmitt

SHAREHOLDER AGREEMENTS IN PUBLICLY TRADED COMPANIES: A COMPARISON BETWEEN THE

U.S. AND BRAZIL. 402 Helena Masullo

REgulaÇÃo DO INVESTIMENTO ESTRANGEIRO DIRETO NO BRASIL: DA RESISTÊNCIA AOS TRATADOS BILATERAIS DE INVESTIMENTO À EMERGÊNCIA DE UM NOVO MODELO REGULATÓRIO 421 Fabio Morosini e Ely Caetano Xavier Júnior

DA QUALIFICAÇÃo JURÍDiCA dAS Distintas FORMAS DE PRESTAÇão TECNOLÓGICA: BREVE ANÁLISE DO MARCO REGULATÓRIO INTERNACIONAL

Daniel Amin Ferraz

REDEFINING TERRORISM: THE DANGER OF MISUNDERSTANDING THE MODERN WORLD'S GRAVEST THREAT

Jennifer Breedon

As EXECUÇões SELETIVAS E A RESPONSABILIZAÇÃo DE AGENTES TERRORISTAS 485 Alexandre Guerreiro

INTERNATIONAL CRIMINALS AND THEIR VIRTUAL CURRENCIES: THE NEED FOR AN INTERNATIONAL EFFORT IN REGULATING VIRTUAL CURRENCIES AND COMBATING CYBER CRIME Joy Marie Virga

Criminalidad transnacional organizada en el Ámbito del MERCOSUR: ¿Hacia un Derecho Penal Regional?. .528 Nicolás Santiago Cordini e Mariano Javier Hoet 
RUMO À INTERNACIONALIZAÇÃo DA PROTEÇÃO PENAL DO MEIO AMBIENTE: DOS ECOCRIMES AO ECOCÍDIO

Kathia Martin-Chenut, Laurent Neyret e Camila Perruso

Engaging the U.N. Guiding Principles on Business and Human Rights: the inter-AMERICAN COMMISSION ON HUMAN RIGHTS \& THE EXTRACTIVE SECTOR 571 Cindy S. Woods

O DIREITO HUMANO À COMUNICAÇÃo PRÉVIA E PORMENORIZADA DAS ACUSAÇÕES NOS PROCESSOS administrativos: O desprezo do Superior Tribunal de Justiça ao Pacto de San José da Costa Rica e À Corte Interamericana de Direitos Humanos .590

Daniel Wunder Hachem e Eloi Pethechust

A responsabilidade internacional do Brasil em FaCe do CONTRole de ConVENCionaliDADE EM SEDE DE DIREITOS HUMANOS: CONFLITO DE INTERPRETAÇÃO ENTRE A JURISDIÇÃO DA Corte Interamericana de Direitos Humanos e o Supremo Tribunal Federal quanto a LEI DE ANISTIA 612

Carla Ribeiro Volpini Silva e Bruno Wanderley Junior

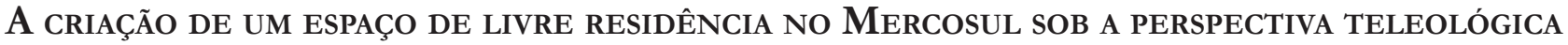
DA INTEGRAÇÃo REGIONAL: ASPECTOS NORMATIVOS E SOCIAIS DOS ACORDOS DE RESIDÊNCIA ....... 631

Aline Beltrame de Moura

A funcionalização como tendênCia evolutiva do Direito Internacional e sua conTRIBUIÇÃO AO REGIME LEGAL DO BANCO DE DADOS DE IDENTIFICAÇÃO DE PERFIL GENÉTICO NO BRASIL

Antonio Henrique Graciano Suxberger

O DIREITO INTERNACIONAL E A PROTEÇÃO DOS DIREITOS DE CRIANÇAS E DE ADOLESCENTES EM CONFLITO COM A LEI EM MOÇAMBIQUE

Bernardo Fernando Sicoche

ObTenÇão de PRovas no EXTERIOR: PARA ALÉM dA LEX FORI E LEX DiLigENTIAE. .685 André De Carvalho Ramos 
A Slight Revenge and a Growing Hope for Mauritius and the Chagossians: The UNClos Arbitral Tribunal's Award of 18 March 2015 on Chagos Marine Protected Area (Mauritius v. United Kingdom)

Géraldine Giraudeau

ANÁLISE DA RESPONSABILIDADE INTERNACIONAL DA UCRÂNIA POR VIOLAÇÃo DOS DIREITOS HUmanos na QUeda do voo da Malaysia Airlines (MH17). .728

Daniela Copetti Cravo

NatureZa JURÍdica do DESENVOLVIMENTO SUSTENTÁVEL No DIREITO INTERNACIONAL ........739 Pedro Ivo Diniz

A INFLUÊNCIA Da SOFT LAW NA FORMaÇão do DiREITo AMBIENTAL .767 Leonardo da Rocha de Souza e Margareth Anne Leister

As COMPLICADAS INTER-RELAÇÕES ENTRE OS SISTEMAS INTERNOS E INTERNACIONAIS DE PROTEÇãO DO DIREITO AO MEIO AMBIENTE SADIO. 785 José Adércio Leite Sampaio e Beatriz Souza Costa 


\title{
A criação de um espaço de livre residência no Mercosul sob a perspectiva teleológica da integração regional: aspectos normativos e sociais dos acordos de residência*
}

\author{
The space creation for free residence in \\ Mercosul under the theleological perspective \\ of regional integration: normative and social \\ aspects of residency agreements
}

Aline Beltrame de Moura**

\section{Resumo}

O Mercosul tem estimulado a adoção de políticas regionais tendentes à valorização da sua dimensão social, alcançando uma esfera até pouco tempo marginalizada pelo processo de integração. Nesse sentido, o cidadão emerge como o centro de diversas medidas adotadas com o escopo de tutelar seus interesses e direitos individuais e coletivos. O objetivo deste artigo consiste em verificar que a entrada em vigor dos Acordos de Residência em dez países latino-americanos simboliza e, acima de tudo, materializa os anseios de uma integração vertical, isto é, que parta da sociedade civil e alcance a esfera institucional do fenômeno regional. A dimensão teleológica da integração é observada ao se vislumbrar que não somente com base no desenvolvimento econômico se constrói o Mercosul, mas, igualmente, com base em uma matriz social cada vez mais presente no quotidiano da população. A metodologia utilizada é a bibliográfica.

Palavras-chave: Cidadania. Processo de integração regional. Mercosul. Direitos e prerrogativas. Residência e migração.

* Recebido em 13/09/2015

Aprovado em 11/10/2015

** Doutora em Direito Internacional pela Università degli Studi di Milano (UNIMI), Itália. Bolsista CAPES Doutorado Pleno no Exterior. Vencedora do Prêmio Riccardo Monaco de melhor tese de doutorado defendida na Itália em 2014 na área do Direito Internacional. Mestre em Direito nas Relações Internacionais pela Universidade Federal de Santa Catarina (UFSC), Bacharel em Direito pela mesma instituição. Pesquisadora Visitante do Max Planck Institute for Comparative and International Private Law em Hamburgo, Alemanha. Membro do Grupo de Pesquisa em Direito Internacional - UFSC/CNPq. Professora substituta da Universidade Federal de Santa Catarina, Professora da Faculdade CESUSC e da Pós-Graduação do Centro Universitário Católica de Santa Catarina. E-mail: alineb.moura@gmail.com.

\section{Abstract}

Mercosul has stimulated the adoption of regional politics aimed to valorize his social dimension, reaching a sphere until then marginalized by the integration process. Accordingly, the citizen emerges as the center of several adopted measures aiming his benefits and individual and collective rights. The purpose of this article is to analyse the Residency Agreement implementation in ten Latin American countries symbolizes, and above all, materializes the wishes of a vertical integration, this is, that departs from the civil society and reaches the institutional sphere at a regional phenomenon. The theleological integration dimension it's observed when glimpsing that not only from the economic development the Mercosul is built, but equally from a social matrix increasingly present in the population's daily basis. The used methodology it's the bibliographic. 
Keywords: Citizenship. Regional integration process. Mercosur. Rights and Prerogatives. Residence and Migration.

\section{INTRODUÇÃO}

O Mercosul se encontra em uma fase do processo de integração bastante peculiar se comparada aos anos imediatamente posteriores ao Tratado de Assunção. De um nascimento marcado pelo predomínio de fatores econômicos e de trocas comerciais, o Mercosul amadureceu, superou crises internas e se fortaleceu em um ponto inimaginável pelos seus idealizadores quando da sua criação: a dimensão social. Âmbito este ainda pouco explorado pelos estudiosos que insistem em fixar suas atenções exclusivamente às controvérsias e fragilidades da integração econômica e comercial, esquecendo que o elemento central de todo este processo é o cidadão. $\mathrm{O}$ objetivo do presente artigo, portanto, consiste em trazer à tona a discussão sobre esta nova perspectiva teleológica da integração, tentando entender e superar o estigma de ineficiência que muitas vezes circundam a análise das questões que envolvem o Mercosul.

Considerando tais premissas, o presente artigo pretende analisar as mais recentes medidas adotadas pelos órgãos do Mercosul no sentido de viabilizar a consolidação da sua dimensão social, em particular, o caminho levado até a assinatura e a entrada em vigor dos Acordos de Residência para os Cidadãos dos Estados Partes do Mercosul, os quais preveem a adoção de procedimentos diferenciados que facilitam a concessão da autorização da residência para os nacionais dos dez Estados que ratificaram tal documento, beneficiando cerca de 400 milhões de pessoas.

Ao analisarmos os benefícios e direitos previstos em tais Acordos, pretende-se verificar em que medida estaríamos diante de um verdadeiro "espaço de livre residência" no Mercosul, embora ainda subsistam os controles aduaneiros e migratórios nas fronteiras nacionais. Conforme será observado, trata-se de um percurso normativo peculiar e instigante que nos leva a refletir sobre os reais anseios e desafios do fenômeno mercosulino.

De forma a auxiliar a pesquisa, a combinação dos métodos sistemático e indutivo estabelece análise mais completa e efetiva acerca do paradigma da circulação de pessoas e da fixação da residência em países pertencen- tes ao Mercosul, haja vista que se trata de um argumento multifacetário, não exaurindo as tarefas da pesquisa apenas no campo jurídico.

\section{A CiRCULAÇÃo dAS PESSOAS NOS PROCESSOS DE INTEGRAÇÃO REGIONAL}

A fim de compreender a atual fase da integração do Mercosul $^{1}$ na perspectiva da circulação e da residência das pessoas na região, parece oportuno distinguir dois conceitos que, frequentemente, são confundidos: migração e da livre circulação. A migração conecta-se à noção de fronteiras fechadas e ao poder de um Estado de controlar o ingresso dos estrangeiros no seu território, enquanto a livre circulação invoca a ideia de fronteiras abertas e a possibilidade dos cidadãos de moverem-se livremente no espaço integrado ${ }^{2}$. Portanto, a noção de livre circulação, inerente a um processo de integração, diferencia-se da noção de migração tradicional, ou seja, daquela entre Estados, tendo em vista que "la libre movilidad migratoria constituye la principal contraparte social de las políticas económicas en espacios regionales de integración ${ }^{3 " .}$

1 O Mercosul, atualmente, possui cinco Estados-membros, quatro Estados Associados. Um se encontra em fase de adesão para se tornar membro a título pleno e dois em fase de adesão para adquirirem a condição de Estado Associado. Além dos Estados fundadores - Argentina, Brasil, Paraguai e Uruguai - também a Venezuela aderiu como Estado-membro em julho de 2012. O último Estado que assinou o Protocolo de adesão para passar da categoria de Estado Associado para Estado-membro foi a Bolívia, em dezembro de 2012, enquanto o Equador já iniciou o processo para satisfazer os requisitos exigidos à admissão. Na pendência da implementação dos mencionados procedimentos, os Estados hoje Associados são Bolívia, Chile, Peru, Colômbia e Equador; recentemente assinaram $\mathrm{o}$ ato de adesão para se tornarem Associados do Mercosul a Guina e o Suriname. Tal dinâmica de expansão, sobretudo nos últimos anos, assinala o relevante papel que está assumindo esta organização internacional na região latino-americana. Nesse sentido, ver ARIETI, Samuel A. Development: the Role of Mercosur as a Vehicle for Latin American Integration. Chicago Journal of International Law, Chigado, v. 6, n. 2, p. 761-773, Jan. 2006. p. 761 ss. Cfr. di recente NASCIMBENE, Bruno. Le droit de la nationalité et le droit des organisations d'intégration régionales. Vers de nouveaux statuts de résidents? Leide: Brill, 2014. (Recueil des Cours de l'Académie de La Haye, 367). p. 382 ss. 2 SANT'ANA, Marcílio Ribeiro de. A livre circulação de trabalhadores no Mercosul. In: Brasil, migrações internacionais e identidade. 2000. Disponível em: <http://www.comciencia.br/reportagens/ migracoes/migr08.htm>. Acesso em: 23 nov. 2014.

3 MÁRMORA, Lelio; PÉREZ, Vichich Nora. Elementos de politicas migratorias para el Mercosur: Informe Nacional de Desarrollo Humano. Buenos Aires: Senado de la Nación Argentina, 1997. p. 267. Veja-se o art. 10 do Tratado de Assunção de 1991 e o art. 3 do Protocolo de Ouro Preto de 1994. O CMC exercita, ademais, a personalidade 
Nesse sentido, a construção do Mercosul pressupõe a redefinição de certos limites. Os deslocamentos internacionais convertem-se em internos e estabelece-se um duplo jogo de fronteiras que se abre às pessoas dos Estado-membros e se fecham aos origináriios dos demais Estados ${ }^{4}$. Nesse caso, os movimentos populacionais ocorridos dentro de um processo de integração regional possuem aspecto sociocultural fundamental capaz de favorecer o aprofundamento da integração ${ }^{5}$, em particular na região do Mercosul, onde existe uma cultura histórica e linguística compartilhadas entre os povos.

De fato, a partir da configuração de uma liberdade de trânsito das pessoas entre os Estados-Partes de uma organização internacional, cujo objetivo primário é o de facilitar o atravessamento das fronteiras inicialmente apenas aqueles que vão trabalhar em um outro Estado da comunidade econômica, desenvolve-se, progressivamente, uma noção de cidadania. Esta delineia os contornos de um estatuto de cidadania no momento em que a mera liberdade de circulação e residência — agora não mais somente dos trabalhadores - se une a outros direitos e deveres que ultrapassam aqueles meramente necessários para a fruição da atividade econômica transfronteiriça $a^{6}$.

Conforme será verificado, no Mercosul é possível, atualmente, vislumbrar a consolidação de relevantes direitos nas mais variadas áreas e que têm como ponto de partida o direito à circulação e, sobretudo, o direito à residência dos cidadãos dos Estados Partes em qualquer um dos países do bloco regional.

jurídica do Mercosul (art. 8 par. 3 do Protocolo). BRASIL. Decreto $n^{\circ}$ 1.901, de 09 de maio de 1996. Disponível em: <http://www.planalto. gov.br/ccivil_03/decreto/D1901.htm>. Acesso em: 15 dez. 2015;

4 MODOLO, Vanina. La movilidad territorial en el Mercado Común Europeo y Mercosureño. In: NOVICK, Susana (Dir.). Migraciones y Mercosur: una relación inconclusa. Buenos Aires: Catálogos: 2010. p. 29-50. p. 33.

5 NOVICK, Susana (Dir.). Introdución, migraciones, políticas e integración regional: avances y desafíos. In: Migraciones y Mercosur: una relación inconclusa. Buenos Aires: Catálogos: 2010. p. 9-28. p. 10. A autora salienta a troca de bens e os movimentos populacionais nos citados territórios, fenômenos registrados antes mesmo da conquista espanhola.

6 GOIZUETA VÉRTIZ, Juana; GÓMEZ FERNÁNDEZ, Itziar; PASCUAL GONZÁLEZ, María Isabel. La libre círculación de personas en los sistemas de integración económica: modelos comparados: Unión Europea, Mercosur y Comunidad Andina. Navarra: Thomson Reuters Aranzadi, 2012. p. 13.

\section{A liberdade de CiRculação No Tratado de AssunÇÃo e NAS PRIMEIRAs dECISÕES do MER- COSUL}

Diferentemente de outros processos de integração regional, como a União Europeia ${ }^{7}$, o Tratado constitutivo do $\mathrm{Mercosul}^{8}$ não previa nenhuma disciplina relativa à liberdade de circulação dos trabalhadores e à abolição de qualquer discriminação em base à nacionalidade entre os trabalhadores dos Estados-membros. Na primeira fase da integração, a única previsão sobre a livre circulação se encontrava no art. 1 do Tratado de Assunção e dizia respeito à liberdade de circulação de bens, serviços, fatores produtivos entre os Estados, sem nenhuma referência direta ao direito de circulação e de residência dos indivíduos.

Apesar da ausência de previsão expressa, o Conselho do Mercado Comum (CMC), desde as primeiras Decisões em 1991, tem manifestado a vontade política de "avanzar en la implementación progresiva de la integración, que implica un espacio regional donde pueden circular libremente los ciudadanos y residentes de los Estados Partes del Mercado Común, asi como sus bienes, servicios y factores productivos". Portanto, o CMC já teve a oportunidade de referenciar a necessidade do estabelecimento de um espaço regional onde os indivíduos, e não somente os trabalhadores, possam livremente circular e residir nos Estados-Partes.

Na recém citada Decisão n. 12/91, os ministros dos respectivos Estados também demonstraram a intenção de criar uma maior fluidez de trânsito por meio da harmonização das leis em matéria de migração. Com tal finalidade, foi previsto a instalação de balcões preferen-

7 Como é notório, o art. 48 do Tratado de Roma de 1957 previa a livre circulação e a abolição de qualquer discriminação baseada na nacionalidade para os trabalhadores dos Estados-membros. União Europeia. 48. TRATADO que institui a Comunidade Económica Europeia ou Tratado CEE - texto original (versão não consolidada). Disponível em: <http://eur-lex.europa.eu/legal-content/PT/ TXT/HTML/?uri=URISERV:xy0023\&from=PT $>$. Acesso em: 15 dez. 2015.

8 O Tratado de Assunção, celebrado em 26 de março de 1991 entre Argentina, Brasil, Paraguai e Uruguai, entrou em vigor em 19 de novembro de 1991. BRASIL. Decreto n 1.901, de 09 de maio de 1996. Disponível em: <http://www.planalto.gov.br/ccivil_03/decreto/ D1901.htm>. Acesso em: 15 dez. 2015

9 MERCOSUl. Conselho do Mercado Comum. Decisão $n^{\circ}$ 12, de 17 de dezembro de 1991. Disponível em: <http://www.mercosur. int/msweb/portal\%20intermediario/Normas/normas_web/Decisiones/PT/CMC_1991_DEC_012_PT_TransitCiudada.PDF>. Acesso em: 15 dez. 2015. Sobre a facilitação para os cidadãos do Mercosul de 17 de dezembro de 1991 em Brasília. 
ciais nos aeroportos e nos portos para os cidadãos e para os residentes destes Países. O objetivo de tais medidas, conforme o próprio texto da Decisão nos informa, era o de contribuir "ao incremento do intercâmbio econômico e comercial e, em especial, turístico". Em outras palavras, nessa fase do processo de integração, não se pensava em facilitar ou promover as migrações propriamente ditas, mas antes em facilitar a mobilidade temporária, de natureza comercial ou turística ${ }^{10}$.

Nesse primeiro período da integração regional, o Grupo Mercado Comum (GMC) tinha elaborado uma lista de documentos de identificação pessoal válidos para a circulação das pessoas no território dos Estados Partes $^{11}$ e tinha auspicado a criação de um documento único de viagem para os seus cidadãos, razão pela qual foi estabelecido um grupo de trabalho ad hoc ${ }^{12}$ que culminou com a criação do passaporte comum do Mercosull $^{13}$ que começou a ser emitido em 2006, seguindo o modelo europeu. Na capa do passaporte, é cunhada a denominação "Mercosul" ou "Mercosur", acima daquela do nome do Estado-membro. Tal documento tem o escopo de uniformizar a qualidade técnica para fins de identificação, facilitando assim os controles. Do ponto de vista simbólico, pretende tornar identificáveis os seus cidadãos no exterior, além de mostrar a existência de uma identidade comum. A Argentina realizou um passo ulterior ao estampar também na carteira de identidade dos seus nacionais a palavra "Mercosur", todavia, não resulta que algum outro Estado-membro tenha adotado

10 AGUIRRE, Orlando; MERA, Gabriela; NEJAMKIS, Lucila. Políticas migratorias e integración regional: la libre circulación y los desafíos a la ciudadanía. In: NOVICK, Susana (Dir.). Migraciones y Mercosur: una relación inconclusa. Buenos Aires: Catálogos: 2010. p. $50-72$, p. 62.

11 MERCOSUL. Grupo Mercado Comum. Resolução n 44, de 03 de agosto de 1994. Disponível em: <http://www.mercosur.int/msweb/ Normas/normas_web/Resoluciones/PT/GMC_RES_1993038_PT_Grupo_AD_HOC_Documento_\%C3\%9Anico_Viagem. PDF>. Acesso em: 15 dez. 2015. Sobre Documentos válidos de cada Estado Parte para a circulação das pessoas no Mercosul. Os documentos válidos para este fim são as carteiras de identidade e os passaportes.

12 MERCOSUL. Grupo Mercado Comum. Resolução $n^{\circ}$ 38, de 30 de junho de 1993. Disponível em: <http://www2.uol.com.br/ actasoft/actamercosul/novo/res_44_94.htm>. Acesso em: 15 dez. 2015. sobre a criação de um Grupo ad hoc para a redação do documento único de viagem em Assunção, Paraguai.

13 MERCOSUL. Grupo Mercado Comum. Resolução $n^{\circ} 40$, de 8 de dezembro de 1998. Disponível em: <http://www.mercosur.int/ innovaportal/v/387/4/innova.front/busqueda-de-normativa $>$. Acesso em: 15 dez. 2015. Sobre Características comuns que devem ter os passaportes, de, Rio de Janeiro, Brasil. medidas do mesmo gênero ${ }^{14}$. De qualquer modo, esse documento "is a sign that MERCOSUR integration is still on course. [...] One very important feature of the MERCOSUR passport is that it enhances workeforce mobility and facilitates cultural and political integration Sometimes this form of integration comes before economic integration." 15

Outros acordos haviam sido igualmente firmados nesse período, muito embora, em âmbito mais limitado, em matéria de coordenação e cooperação entre os Estados para o controle das fronteiras ${ }^{16}$, dentre os quais se destaca o Acordo de Recife de $1993^{17}$ que consagrou

14 FLÔRES JUNIOR, Renato G. Símbolos e integrações regionais: uma breve introdução com vistas ao Mercosul. In: HOFMEISTER, Wilhelm. União Europeia e Mercosul: dois momentos especiais da integração regional. Rio de Janeiro: Fundação Konrad Adenauer no Brasil, abr. 2007. (Cadernos Adenauer, 1). p. 17-31. p. 23.

15 VALADÃO, Marcos Aurelio Pereira. Legal and institutional dimensions of reform: Washington Consensus and Latin America integration: Mercosur and the road to regional inconsistencies - to where are we going exactly?. Law and Business Review of the Americas, Dallas, v. 15, n. 1, p. 207-220, 2009. p. 216.

16 MERCOSUL. Conselho do Mercado Comum. Decisão $n^{\circ} 18$, de 07 de dezembro de 1999. Disponível em: < http://www.mercosur.int/ msweb/Normas/normas_web/Decisiones/PT/Dec_018_099_ Tr\%C3\%A2nsito $\% 20$ Vicinal $\% 20$ Fronteiri $\%$ C3\%A7o\%20MCS_ Ata\%202_99.PDF>. Acesso em: 15 dez. 2015 com relação ao Acordo sobre o trânsito vicinal transfronteiriço entre os Estados Partes do Mercosul; MERCOSUL. Conselho do Mercado Comum. Decisão $n^{\circ}$ 19, de 07 de dezembro de 1999. Disponível em: <http:// www.mercosur.int/msweb/portal\%20intermediario/Normas/normas_web/Decisiones/PT/Dec_019_099_Tr\%C3\%A2nsito\%20 Vicinal $\% 20$ Front $\% 20 \mathrm{MCS} \% 20 \mathrm{Bol} \% 20$ Chile_Ata $\% 202 \_99 . P D F>$. Acesso em: 15 dez. 2015 que estende o acordo também a Bolívia e Chile; MERCOSul. Conselho do Mercado Comum. Decisão $n^{\circ}$ 14, de 29 de junbo de 2000. Disponível em: <http://gd.mercosur.int/ SAM \%5CGestDoc\%5Cpubweb.nsf/AA30EDC2D55AF15D032 57F1D00490651/\$File/DEC_014-2000_PT_Regul\%20Reg\%20 Tr\%C6\%92nsito $\% 20$ Vicinal $\% 20$ Fronteiri $\%$ E2\%80\%A1o_Ata $\% 20$ 1_00.pdf>. Acesso em: 15 dez. 2015 que regulamenta as decisões precedentes, criando a Credencial de Trânsito Vicinal nas Fronteiras (TVF) que permite ao beneficiário permanecer no território do país vizinho por até 72 horas; MERCOSUL. Conselho do Mercado Comum. Decisão n 15, de 29 de junho de 2000. Disponível em: <http:// gd.mercosur.int/SAM\%5CGestDoc\%5Cpubweb.nsf/C53D520147 0B3A1503257F1D0049314D/\$File/DEC_015-2000_PT_Reg\%20 Tr\%C6\%92nsito $\% 20$ Vicin $\% 20$ Front $\% 20$ MCS $\% 20 B$ Bl $\% 20$ Chile_ Ata\%201_00.pdf>. Acesso em: 15 dez. 2015 estende esta regulamentação também à Bolívia e ao Chile.

17 MERCOSUL. Conselho do Mercado Comum. Decisão $n^{\circ}$ 05, de 22 de abril de 1993. Disponível em: <http://gd.mercosur.int/ SAM/GestDoc/PubWeb.nsf/OpenFile?OpenAgent\&base $=$ SAM $\backslash$ GestDoc $\backslash$ DocOfic0Arch.nsf\&id=832579C700726F0D 832577 810052E8A2\&archivo=RES_005_1993-PT_Comiss\%F5es\%20 SGTs $\% 20 \mathrm{~N} \% \mathrm{~B} 0 \% 202, \% 207, \% 2010 . \mathrm{doc}>$. Acesso em: 15 dez. 2015 sobre Aplicação dos Controles integrados de Fronteiras entre os Países do Mercosul de $1^{\circ}$ de julho de 1993 em Assunção, Paraguai. Recentemente, tal disciplina foi integrada pela Dec. CMC n. 07/12 sobre a Complementação ao Acordo de Recife em matéria 
o conceito de "controle integrado de fronteiras", estabelecendo procedimentos administrativos e operativos que fossem comuns e integrados entre os Estados Partes para o controle da entrada e da saída das pessoas no seus territórios.

A dimensão migratória da integração foi contemplada pelo Programa de Ação do Mercosul de $1995^{18}$, segundo o qual o desenvolvimento do fenômeno regional no sentido de promover o mercado comum requer aprofundamento do tema das migrações nos seus diversos aspectos, dentre os quais o controle das fronteiras e o exame da possibilidade de coordenação das políticas migratórias dos Estados-Partes ${ }^{19}$.

Segundo as orientações traçadas pelo citado Programa de Ação, foi aprovada a criação de um modelo único do "Cartão de entrada e saída" ${ }^{20}$, ou seja, de uma declaração solicitada aos indivíduos que se desloquem de um Estado-Parte para outro através de meios de transporte aéreos, fluviais, marítimos e terrestres. Com relação aos aspectos institucionais e à necessidade de centralizar o sistema de troca de informações relativos à autenticidade dos documentos de viagem dos respectivos cidadãos, foi aprovada a criação dos Centros de Consulta de

migratória, adotada em 29 de junho de 2012 em Mendonça, Argentina. MERCOSUL. Conselho do Mercado Comum. Decisão $n^{\circ}$ 07, de 29 de junho de 2012. Disponível em: <http://gd.mercosur.int/ SAM\%5CGestDoc\%5Cpubweb.nsf/A2829874C636D36B03257F 1D0049FB6C/\$File/DEC_007-2012_PT_Complementacao\%20 Acordo $\% 20$ Recife $\% 20$ Materia $\% 20$ Migratoria.pdf $>$. Acesso em: 15 dez. 2015.

18 MERCOSUL. Conselho do Mercado Comum. Decisão n ${ }^{\circ}$ 9, de 5 de outubro de 1995. Disponível em: <http://gd.mercosur.int/SAM/ GestDoc/PubWeb.nsf/OpenFile?OpenAgent\&base=SAM $\backslash$ GestDoc $\backslash$ DocOfic0Arch.nsf\&id $=832579$ C700726F0D83257751006F6 800\&archivo $=$ DEC_008-1995_PT_Prot $\% 20 \mathrm{Harm} \% 20$ Norm $\% 20$ Intelect $\% 20$ Proc $\% 20$ Denom $\% 20$ Origem_Ata $\% 201$-95.doc $>$. Acesso em: 15 dez. 2015. sobre o Programa de Ação do Mercosul até o ano de 2000.

19 MERCOSUL. Conselho do Mercado Comum. Decisão n 9, de 5 de outubro de 1995. Disponível em: <http://gd.mercosur.int/SAM/ GestDoc/PubWeb.nsf/OpenFile?OpenAgent\&base=SAM $\backslash$ GestDoc $\backslash$ DocOfic0Arch.nsf\&id $=832579$ C 700726F0D83257751006F6 800\&archivo=DEC_008-1995_PT_Prot $\% 20$ Harm $\% 20$ Norm $\% 20$ Intelect $\% 20$ Proc $\% 20$ Denom $\% 20$ Origem_Ata $\% 201$-95.doc $>$. Acesso em: 15 dez. 2015.

20 MERCOSUL. Grupo Mercado Comum. Resolução nº 58, de 21 de junho de 1996. Disponível em: <http://gd.mercosur.int/SAM/ GestDoc/PubWeb.nsf/OpenFile?OpenAgent\&base $=$ SAM $\backslash$ GestDoc $\backslash$ DocOfic0Arch.nsf\&id $=832579$ C 700726F0D 8325775900 565BEF\&archivo=RES_058-1996_PT_Cart\%E3oEntrada $\% 20$ Saida\%20(CES).doc>. Acesso em: 15 dez. 2015 em Buenos Aires, Argentina. A Resolução entrou em vigor 180 dias após a data da assinatura $\left(\operatorname{art} .7^{\circ}\right)$.
Documentos Pessoais do Mercosul em 199621, os quais deveriam ter a tarefa de facilitar o controle migratório e a circulação de um modo geral. Todavia, ao verificarmos os órgãos nacionais que seriam atualmente responsáveis por esse tipo de controle ${ }^{22}$, parece que os citados Centros jamais foram efetivamente criados e colocados em funcionamento, tendo em vista que não se encontra nenhuma informação a respeito.

Nos anos 2000, foi firmado o Acordo sobre a Isenção de $\operatorname{Vistos}^{23}$, mas possuía âmbito subjetivo de aplicação limitado à categoria de trabalhadores migrantes e aos que exercitam determinadas profissões, tais como artistas, professores, cientistas, atletas, jornalistas, profissionais liberais ou técnicos especializados. O Acordo prevê que essas categorias poderiam permanecer no território de um outro Estado-membro por 90 dias (prorrogáveis pelo mesmo período) até um máximo de 180 dias por ano, sem a necessidade de visto. Resta evidente que, dessa forma, se afasta da ideia de livre circulação regional ao mesmo tempo em que se submete o tema migratório aos critérios nacionais, de caráter mais restritivo $^{24}$. Todavia, até hoje, apenas o Brasil ratificou o Acordo, não se encontrando, portanto, vigente ${ }^{25}$.

21 MERCOSUL. Grupo Mercado Comum. Resolução n 59, de 21 de junho de 1996. Disponível em: <http://gd.mercosur.int/SAM/ GestDoc/PubWeb.nsf/OpenFile?OpenAgent\&base=SAM $\backslash$ GestDoc $\backslash$ DocOfic0Arch.nsf\&id $=832579$ C700726F0D832577590057C CDC\&archivo=RES_059-1996_PT_Cria\%E7\%E3oCentrosConsu IDocuPersonales.doc >. Acesso em: 15 dez. 2015 em Buenos Aires, Argentina.

22 O art. 3 e 4 da Res. GMC n. 59/96 expressamente definiu quais deveriam ser os órgãos nacionais responsáveis pelo estabelecimento da sede e pela administração do funcionamento interno dos Centros. MERCOSUL. Grupo Mercado Comum. Resolução n 59, de 21 de junbo de 1996. Disponível em: <http://gd.mercosur.int/SAM/ GestDoc/PubWeb.nsf/OpenFile?OpenAgent\&base=SAM $\backslash$ GestDoc $\backslash$ DocOfic0Arch.nsf\&id=832579C700726F0D832577590057C CDC\&archivo=RES_059-1996_PT_Cria\%E7\%E3oCentrosConsu IDocuPersonales.doc $>$. Acesso em: 15 dez. 2015

23 MERCOSUL. Conselho do Mercado Comum. Decisão $n^{\circ} 48$, de 14 de dezembro de 2000. Disponível em: <http://gd.mercosur.int/ SAM\%5CGestDoc\%5Cpubweb.nsf/6420A63D340570CA03257 F1D004AF9BF/\$File/DEC_048-2000_PT_FERR_Acordo $\% 20$ Isen $\%$ E $2 \% 80 \% \mathrm{~A} 1 \% \mathrm{C} 3 \% 860 \% 20 \mathrm{de} \% 20$ Vistos_Ata $\% 202 \_00$. pdf > . Acesso em: 15 dez. 2015. sobre a Isenção de Vistos entre os Estados Partes do Mercosul de 14 de dezembro de 2000, adotada em Florianópolis, Brasil.

24 AGUIRRE, Orlando; MERA, Gabriela; NEJAMKIS, Lucila. Políticas migratorias e integración regional: la libre circulación y los desafíos a la ciudadanía. In: NOVICK, Susana (Dir.). Migraciones y Mercosur: una relación inconclusa. Buenos Aires: Catálogos: 2010. p. $50-72$. p. 14.

25 O art. 8 do Acordo prevê que o mesmo entrará em vigor a partir da ratificação do segundo Estado Parte, de modo bilateral, até 


\section{OS ACORDOS SOBRE MIGRAÇÃO E RESIDÊNCIA DE 2002}

O salto qualitativo na matéria de migração e circulação de pessoas dentro do espaço territorial do Mercosul ocorreu durante a XXIII Reunião do Conselho Mercado Comum entre os dias 5 e 6 de dezembro de $2002^{26} \mathrm{com}$ a assinatura de Acordos sobre a Migração e a Residência dos cidadãos dos Estados-Partes do Mercosul. Diferentemente do que se possa imaginar, esses Acordos não preveem nenhum requisito ligado à situação socioeconômica ou laboral do migrante, a condição principal para ser beneficiário desses direitos é somente aquela de ser titular da nacionalidade de um dos Estados Partes.

Para maior clareza, é oportuno precisar que dois são os Acordos sobre a Regularização das Migrações Internas dos Cidadãos do Mercosul, de idêntico conteúdo mas com Estados contraentes diferentes. O primeiro foi assinado apenas pelos Estados-membros fundadores do Mercosul; já o segundo teve a participação também da Bolívia e do Chile, ambos Estados Associados. A mesma situação constata-se com relação aos dois Acordos sobre Residência para os Cidadãos dos Estados-Parte do Mercosul, isto é, o primeiro foi assinado pelos Estados-Membros e o segundo também por Bolívia e Chile. De qualquer modo, a sua relevância consiste em acolher uma série de solicitações inerentes à necessidade de criação de um espaço integrado ${ }^{27}$, manifestadas pelos diversos atores do Mercosul desde o início do processo de integração.

Diferentemente do que possa parecer em um primeiro momento, tais Acordos não devem ser confundidos com as Decisões do Conselho Mercado Comum. Os Acordos sobre Migração e sobre Residência constituem, de fato, autênticos instrumentos internacionais

que os outros Estados realizem o procedimento de incorporação. BRASIL. Decreto $n^{\circ}$ 6.975, de 7 de outubro de 2009. Disponível em: <http://www.planalto.gov.br/ccivil_03/_Ato2007-2010/2009/Decreto/D6975.htm>. Acesso em: 15 dez. 2015.

26 Reunião ocorrida em Brasília, Brasil, entre os dias 5 e 6 de dezembro de 2002.

27 REVELEZ, Lincoln Bizzozero. La educación superior en el Sector Educativo del Mercosur: impactos en la migración intrarregional y perspectivas en el proceso de integración. In: LAS MIGRACIONES humanas en el Mercosur: una mirada desde los derechos humanos, compilación normativa. Montevideo: Observatório de Políticas Públicas de Derechos Humanos en el Mercosur, 2009. p. 35-46. p. 41. na medida em que foram elaborados e assinados pelos Chefes de Estado e de Governo. Somente com a Decisão CMC n. 28/02 28 ocorreu a incorporação dos citados Acordos e, assim, as normas internacionais se tornaram realmente direito do Mercosul. Recorda-se que, dado o caráter intergovernamental do bloco, as Decisões do CMC são, em regra, atos não vinculantes e que precisam se submeter ao procedimento de incorporação em cada Estados-Partes a fim de tornarem-se vigentes.

Considerando-se tal situação, diante do retardo do Paraguai em realizar a ratificação do Acordo sobre a Residência, os outros Estados-membros começaram a aplicá-lo de modo bilateral, por meio da troca de instrumentos das respectivas ratificações: isto ocorreu a partir de 3 de abril de 2006 entre Argentina e Brasil; de 20 de julho de 2006 entre Argentina e Uruguai; e de 23 de outubro de 2006 entre Brasil e Uruguai ${ }^{29}$. Os Acordos sobre Residência para os Cidadãos dos Estados-Partes, na qualidade de normas do Mercosul, entraram em vigor para todos os Estados-Membros somente em 28 de julho de 2009, após o depósito da ratificação pelo Paraguai.

Por sua vez, o Acordo sobre a Regularização das Migrações Internas não se encontra atualmente em vigor, pois falta a ratificação da Argentina. Todavia, tal situação não se vislumbra como um problema, uma vez que as disposições deste último repetem-se substancialmente nos Acordos sobre Residência. Oito são os artigos que compõem os Acordos sobre Migração, dos quais apenas quatro apresentam um conteúdo substancial, enquanto os outros disciplinam aspectos meramente formais, como a entrada em vigor e a possibilidade de denúncia.

Os dois Acordos sobre Migração estabelecem, nos art. 1 e 2, que o nacional de um Estado-Parte que se encontre em território de outro Estado-Parte poderá efetuar a tramitação migratória de sua residência nesse último, sem necessidade de sair deste e independente da condição migratória em que houver ingressado o

28 MERCOSUL. Conselho do Mercado Comum. Decisão n 48 , de 6 de dezembro de 2002. Disponível em: < hhttp://www.sice.oas.org/ trade/mrcsrs/decisions/dec2802p.asp>. Acesso em: 15 dez. 2015.

29 SALZMANN, Antonio Cardesa. El contenido jurídico de la libre circulación de personas en el Mercosur: balance y perspectivas. In: GOIZUETA VÉRTIZ, Juana; GÓMEZ FERNÁNDEZ, Itziar; PASCUAL GONZÁLEZ, María Isabel. La libre círculación de personas en los sistemas de integración económica: modelos comparados: Unión Europea, Mercosur y Comunidad Andina. Navarra: Thomson Reuters Aranzadi, 2012. p. 163-185. p. 169. 
peticionante, estando isento do pagamento de qualquer multas ou de outras sanções administrativas mais gravosas. Por outro lado, o art. 3 dos Acordos sobre Residência preveem a mesma regra, acrescentando que o procedimento também pode ser realizado antes do ingresso do indivíduo no território do Estado-Parte de recepção. Dessa forma, a ausência da entrada em vigor dos Acordos Migratórios é, de certa forma, compensada pela eficácia já adquirida pelas disposições contidas nos Acordos sobre Residência.

Muito embora não tenham entrado em vigor, relevante salientar que o propósito dos Acordos sobre Migração consiste em transformar "situações de fato" em "situações de direito", a fim de permitir o funcionamento dos outros dois Acordos sobre Residência ${ }^{30}$. Era necessário que os primeiros, de âmbito mais amplo e geral, fornecessem as bases para a posterior aplicação daqueles sobre a residência que, por sua vez, contém normas procedimentais e específicas, cujo escopo consistia em evitar eventuais conflitos entre as legislações internas dos Estados Partes.

Compreende-se, assim, porque os Acordos sobre Migração tenham sido elaborados com a finalidade de orientar aqueles sobre a Residência. Estes, inclusive, são claros ao afirmar que a "implementação de uma política de livre circulação de pessoas na Região é essencial" porque tem o escopo de "fortalecer e aprofundar o processo de integração, assim como os fraternais vinculos existentes entre eles31". Com tal propósito, torna-se necessário estabelecer regras co-

30 Assim REVELEZ, Lincoln Bizzozero. La educación superior en el Sector Educativo del Mercosur: impactos en la migración intrarregional y perspectivas en el proceso de integración. In: LAS MIGRACIONES humanas en el Mercosur: una mirada desde los derechos humanos, compilación normativa. Montevideo: Observatório de Políticas Públicas de Derechos Humanos en el Mercosur, 2009. p. 35-46. p. 41. O autor continua afirmando que a existência de acordos deste tipo mostra-se relevante não somente se considerado o número de imigrações. Segundo o Ministério de Interior da Argentina cerca de 300 mil argentinos vivem nos outros países do Mercosul, incluindo os Associados. Além disso, 1,2 milhão de paraguaios, 1 milhão de bolivianos, 200 mil uruguaios, 200 mil chilenos e 20 mil brasileiros vivem na Argentina, sendo que a maior parte se encontra na clandestinidade. Cf.: Terra Actualidad (2002) Habrá libertad de tránsito y residencia en el Mercosur, 9 de novembro de 2002. 31 Cfr. Preâmbulo dos Acordos sobre Residência, MERCOSUL. Conselho do Mercado Comum. Decisão n 13, de 5 de julho de 2002. Disponível em: <http://www.mercosur.int/msweb/Normas/normas_web/Decisiones/PT/Dec_013_002_Acordo\%20Antidumping\%20OMC_Ata\%201_02.PDF $>$. Acesso em: 15 dez. 2015; MERCOSUL. Conselho do Mercado Comum. Decisão n ${ }^{\circ} 14$, de 5 de julho de 2002. Disponível em: <http://www.sice.oas.org/trade/mrcsrs/ decisions/dec1402p.asp>. Acesso em: 15 dez. 2015. muns que disciplinem a situação migratória dos cidadãos dos Estados-Partes e que se apresentem, portanto, como um instrumento do início de uma livre circulação e residência de pessoas na região do Mercosul.

Superada essa questão, reforça-se que a importância dos Acordos sobre Residência é confirmada pelas posteriores aprovações dos pedidos de adesão apresentados pelo Peru ${ }^{32}$ e Equador em $2011^{33}$ e pela Colômbia em $2012^{34}$. A Venezuela é o único país que ainda não ratificou tais documentos. Dessa forma, atualmente, os Acordos sobre Residência para os Cidadãos do Mercosul estão em vigor em quatro Estados-membros e em todos os Estados Associados, totalizando nove países, cuja população beneficiada gira em torno de $500 \mathrm{mi}-$ lhões de pessoas. São eles: Argentina, Brasil, Uruguai, Paraguai, Bolívia, Chile, Peru, Equador e Colômbia.

\subsection{Os direitos e prerrogativas previstos nos acordos sobre residência para os cidadãos dos estados-parte do Mercosul}

No tocante às disposições normativas dos Acordos sobre Residência, é curioso notar que, segundo o art. 2, os seus beneficiários são os "Nacionais de uma Parte"; todavia, a definição de "nacionais" que podem gozar de tais direitos é limitada às pessoas que tenham a nacionalidade originária de um dos Estados-Partes ou a nacionalidade adquirida por naturalização há pelo menos cinco anos. Esse tratamento diferenciado poderia

32 O Peru decidiu que o acordo deveria entrar em vigor na mesma data da assinatura do ato de adesão à Dec. CMC n. 4/11, ou seja, em 28 de junho de 2011. MERCOSUL. Conselho do Mercado Comum. Decisão $n^{\circ} 4$, de 28 de junho 2011. Disponível em: <http:/ gd.mercosur.int/SAM $\% 5 C G e s t D o c \% 5 C$ pubweb.nsf/E1B5E57 FB6D43E1F03257F1D004C3DCB/\$File/DEC_004-2011_PT_ Ades $\%$ C3\%860\%20Peru $\% 20$ Acordo $\% 20$ Residen $\% 20$ Nacionais. pdf $>$. Acesso em: 15 dez. 2015.

33 O Equador assinou a Dec. CMC n. 21/11 em 28 de junho de 2011 e decidiu o acordo deveria entrar em vigor após a ratificação pela Assembleia Nacional equatoriana, ocorrida em 3 de dezembro de 2013. MERCOSUL. Conselho do Mercado Comum. Decisão $n^{\circ}$ 21, de 28 de junho 2011. Disponível em: <http://gd.mercosur.int/ SAM\%5CGestDoc\%5Cpubweb.nsf/852556C938D1A7D703257 F1D004C7D16/\$File/DEC_021-2011_PT_Ades $\%$ C3\%860\%20 Equador\%20Residen\%20Nacionais.pdf $>$. Acesso em: 15 dez. 2015. 34 Do mesmo modo do Peru, a Colômbia decidiu que o acordo deveria entrar em vigor na mesma data da assinatura do ato de adesão à Dec. CMC n. 20/12, ou seja, em 29 de junho de 2012. MERCOSUL. Conselho do Mercado Comum. Decisão $n^{\circ}$ 20, de 29 de junho 2012. Disponível em: < http://www.cartillaciudadania.mercosur.int/uploads/DEC_020-2012_PT_Adesao $\% 20 C o l \% 20$ Acordo $\% 20$ Resid $\%$ C3\%AAncia.pdf>. Acesso em: 15 dez. 2015. 
suscitar questionamentos sobre uma eventual discriminação, dado que permitiria, em última análise, que dois indivíduos que tenham adquirido a nacionalidade por naturalização em um dos Estados Partes não recebam o mesmo tratamento no âmbito do Mercosul em razão do tempo transcorrido da data da conclusão do procedimento interno de naturalização ${ }^{35}$.

Com relação aos beneficiários dos direitos elencados pelos Acordos, é interessante notar que os destinatários são tanto os nacionais dos Estados Partes que tenham migrado para outro Estado-Parte quanto os seus familiares, mesmo sendo nacionais de Estados terceiros. Portanto, os familiares gozam de todos os direitos concedidos aos beneficiários primários sem que haja qualquer discriminação em relação ao tratamento oferecido a um cidadão do Mercosul ${ }^{36}$.

Nesse sentido, o art. 9, $\$ 2^{\circ}$ dos Acordos sobre Residência disciplinam acerca do reagrupamento familiar. Permite-se, portanto, aos membros da família de um cidadão do Mercosul que não tenha a nacionalidade de um destes países, a aquisição da autorização de residência idêntica ao do nacional de um Estado-Parte, desde que, é claro, não existam impedimentos de ordem pública ou segurança pública.

35 Nesse sentido, como é notório, interessante recordar que este tipo de diferenciação não encontra guarida no âmbito da União Europeia que, no art. 9 do Tratado de Lisboa, dispõe que "É cidadão da União Europeia qualquer pessoa que tenha a nacionalidade de um Estado-Membro" sem fazer alguma distinção em relação ao modo de aquisição da nacionalidade. PORTUGAL. Comissão de Assuntos Europeus da Assembleia da República. Tratado de Lisboa: versão consolidada. Disponível em: <https://www.parlamento.pt/europa/ Documents/Tratado_Versao_Consolidada.pdf $>$. Acesso em: 15 dez. 2015.

36 De modo a complementar o estudo, ressalta-se que o mesmo ocorre na União Europeia. Dentre outras prescrições europeias sobre o assunto, pode-se recordar o Considerando 20 da Diretiva n. 2004/38/CE: "Em conformidade com a proibição da discriminação em razão da nacionalidade, todos os cidadãos da União e membros das suas famílias que residam num Estado-Membro com base na presente diretiva deverão beneficiar, nesse Estado-Membro, de igualdade de tratamento em relação aos nacionais nos domínios abrangidos pelo Tratado, sob reserva das disposições específicas expressamente previstas no Tratado e no direito secundário" Nesse sentido, ver: ALEXOVIČOVÁ, Iveta. The right of citizenship of the Union and their family members to move and reside freely within the territory of the Member States. In: SCHNEIDER, Hildegard. Migration, Integration and Citizenship: a challenge for Europe's future. Maastricht: Forum Maastricht, 2005. p. 73-105; CONDINANZI, Massimo; LANG, Alessandra; NASCIMBENE, Bruno. Cittadinanza dell'Unione e libera circolazione delle persone. 2. ed. Milano: Giuffrè, 2006; PAGANO, Emmanuele. Ricongiungimento familiare, cittadinanza e residenza: dal caso Zambrano al caso Dereci. Diritto comunitario e degli scambi internazionali, v. 51, n. 3, p. 467-475, 2012. p. 467-475.
Além disso, como os destinatários de tais normas são os nacionais enquanto tais, independentemente da condição laboral, pode-se afirmar que o cerne do direito à livre residência das pessoas encontra-se no art. $9, \$ 1^{\circ}$, o qual prevê a concessão do tratamento nacional em matéria de direitos civis, sociais, culturais e econômicos aos cidadãos dos Estados-Partes e aos seus familiares. Possuem estes, portanto, o direito de associação para fins lícitos, de liberdade de pensamento e de expressão, de professar e praticar livremente a própria religião, o direito de usar a própria língua, os tratamentos relativos à segurança social, aos direitos de uma igual retribuição em condições análogas de trabalho e o direito de fundar sindicatos ou de aderir a estes.

$\mathrm{Na}$ prática, todavia, verifica-se a ausência de uma atuação mais incisiva no sentido de preconizar tais paridades de tratamento por meio de políticas nacionais com esta finalidade específica. Sob tal perspectiva, um expoente do Departamento de Direitos Humanos da Presidência da República brasileira, ao comentar as normas previstas pelo Acordo sobre Residência, manifestou a vontade de conceder aos estrangeiros do Mercosul condições mais facilitadas de ingresso e residência, incluindo os direitos relativos ao trabalho e a uma plena cidadania $^{37}$. Nesse sentido, pode ser mencionada uma iniciativa do governo do Estado de São Paulo a fim de equiparar o tratamento dispensado aos trabalhadores do Mercosul com o concedido aos cidadãos brasileiros, oferecendo programas de qualificação profissional aos trabalhadores estrangeiros que se encontrem em uma situação vulnerável, como frequentemente ocorre com nacionais bolivianos e paraguaios no Brasil ${ }^{38}$.

A igualdade de tratamento, de acordo com o art. 9, $\$ 3^{\circ}$, é também estendida a todas as questões que con-

37 Entrevista concedia por Maria do Rosario. Agência Brasil. NUNES, Maria do Rosário. Após morte de Brayan, ministra vai debater situação de bolivianos no país. Folha de São Paulo. São Paulo, 1 jul. 2013. Disponível em: <http://www1.folha.uol.com. br/cotidiano/2013/07/1304235-apos-morte-de-brayan-ministravai-debater-situacao-de-bolivianos-no-pais.shtml>. Acesso em: 10 out. 2013.

38 ROLLI, Claudia. Governo paulista pretende qualificar estrangeiros. Folha de São Paulo. São Paulo, 11 ago. 2013. Disponível em: <http://www1.folha.uol.com.br/mercado/2013/08/1324746governo-paulista-pretende-qualificar-estrangeiros.shtml>. Acesso em: 10 out. 2013. Segundo a reportagem, na região metropolitana da cidade de São Paulo vivem cerca de 275 mil bolivianos, 45 mil paraguaios e 20 mil peruanos. Estima-se que de 80 a 100 mil dos trabalhadores sul-americanos se contraem em condição irregular, tendo em vista que muitos desenvolvem atividades análogas ao de escravidão. 
cernem a aplicação da legislação em matéria de trabalho. Os Acordos têm abrangência ampla, pois se trata de um princípio que compreende os direitos de exercitar qualquer atividade, autônoma ou subordinada, nas mesmas condições dos cidadãos do País de recepção, incluindo a aplicação da legislação trabalhista, em particular a da remuneração, das condições de trabalho e de previdência social ${ }^{39}$.

Seguindo a mesma orientação, o art. $8, \S 2^{\circ}$ estabelece que as pessoas que obtenham a residência no respeito das regras estabelecidas pelos Acordos têm o direito de trabalhar e de exercitar qualquer atividade, por conta própria ou de outrem, nas mesmas condições dos cidadãos do país de acolhimento. Nesse sentido, porém, surpreende a falta de previsão de exceções ao princípio de não discriminação em base à nacionalidade para as atividades que normalmente são reservadas somente aos cidadãos natos ${ }^{40}$, tais como determinados empregos na administração pública e certas atividades que impliquem o exercício do poder público. Apesar dessas imprecisões normativas, o princípio da igualdade é considerado nos Acordos como um elemento inerente ao espaço de livre residência das pessoas no mercado co-

39 Art. 8. 2. "[os imigrantes] Têm ainda, direito a exercer qualquer atividade, tanto por conta própria, como por conta de terceiros, nas mesmas condições que os nacionais do país de recepção, de acordo com as normas legais de cada país. [...] Art. 9. 3. Igualdade de tratamento com os nacionais: Os imigrantes gozarão, no território das Partes, de tratamento não menos favorável do que recebem os nacionais do país de recepção, no que concerne à aplicação da legislação trabalbista, especialmente em matéria de remuneração, condições de trabalho e seguro social." (Grifo do Autor). MERCOSUL. Conselho do Mercado Comum. Acordo sobre residência para nacionais dos estados partes do Mercosul, Bolivia e Chile. Disponível em: <http://www.mercosur.int/innovaportal/ file/5838/1/56-acuerdoresidenciamsur-boliviaychile.pdf $>$. Acesso em: 15 dez. 2015.

40 A título exemplificativo, o Brasil no art. 222 da Constituição Federal estabelece que "A propriedade de empresa jornalística e de radiodifusão sonora e de sons e imagens é privativa de brasileiros natos ou naturalizados bá mais de dez anos, on de pessoas jurídicas constituídas sob as leis brasileiras e que tenham sede no País." Do mesmo modo, o art. $12, \$ 3^{\circ}$ prevê que "São privativos de brasileiro nato os cargos: de Presidente e Vice-Presidente da República; de Presidente da Câmara dos Deputados; de Presidente do Senado Federal; de Ministro do Supremo Tribunal Federal; da carreira diplomática; de oficial das Forças Armadas; de Ministro de Estado da Defesa." As Cartas Constitucionais dos outros Estados Partes do Mercosul preveem exceções análogas: Argentina (art. 48, 55 e 89); Paraguai (art. 162, 221, 223, 228 e 258); Uruguai (art. 90, 99, 151, 235, 242, 245, 247 e 264); Venezuela (art. 160, 188 e 227). BRASIL. Câmara dos Deputados. Constituiç̃os dos países do Mercosul, 1996-2000: textos constitucionais Argentina, Bolívia, Brasil, Chile, Paraguai e Uruguai. Brasília: Câmara dos Deputados, 2001. Disponível em: <http://www.planalto. gov.br/ccivil_03/Constituicao/Constituicao.htm>. Acesso em: 15 dez. 2015. mum, que goza de um valor jurídico mais relevante que aquele expresso na Declaração Sócio-Laboral de $1988^{41}$, dotada de um mero valor exortativo e não vinculante ${ }^{42}$.

Retomando a análise do Acordo sobre Residência, o art. 9, $₫ 5^{\circ}$ reconhece o direito de transferir dinheiro, permitindo, assim, aos imigrantes de transferir a sua renda e as suas economias ao país de origem, segundo a legislação interna de cada Estado Parte. Trata-se de um tema relevante no âmbito latino-americano e também interamericano, dado que um estudo realizado pelo Fundo Multilateral de Investimentos do Banco Interamericano de Desenvolvimento conjuntamente com o Pew Hispanic Center ${ }^{43}$, constatou que esse tipo de transferência, em certos casos, pode ultrapassar os fluxos de assistência oficial para o desenvolvimento nacional, representando, em alguns países, cerca de $15 \%$ do produto interno líquido $^{44}$ e quase a metade dos investimentos diretos que recebe a região ${ }^{45}$.

Um outro importante direito previsto pelo art. 9, $\$ 6^{\circ}$ refere-se aos filhos dos migrantes. A estes são garantidos o direito ao nome, ao registro de nascimento e à aquisição da nacionalidade, em conformidade

41 O documento, assinado em 10 de dezembro de 1998 no Rio de Janeiro estabeleceu princípios programáticos de integração regional, sendo dividido em quatro partes principais. As primeiras duas referem-se ao conteúdo privado das relações trabalhistas, ou seja, aos direitos individuais e coletivos. As últimas, por sua vez, concernem aos aspectos públicos, como os vinculados às obrigações estatais, os quais foram chamados de "outros direitos" e às regras de "aplicação e seguimento" com relação à vigência do instrumento. MERCOSUL. Declaração Sociolaboral do Mercosul. Disponível em: <http:// bd.camara.gov.br/bd/bitstream/handle/bdcamara/10092/constituicoes_mercosul.pdf $>$. Acesso em: 15 dez. 2015

42 SALZMANN, Antonio Cardesa. El contenido jurídico de la libre circulación de personas en el Mercosur: balance y perspectivas. In: GOIZUETA VÉRTIZ, Juana; GÓMEZ FERNÁNDEZ, Itziar; PASCUAL GONZÁLEZ, María Isabel. La libre círculación de personas en los sistemas de integración económica: modelos comparados: Unión Europea, Mercosur y Comunidad Andina. Navarra: Thomson Reuters Aranzadi, 2012. p. 163-185. p. 171.

43 REMITTANCE Senders and Receivers: tracking the transnational channels. Washington: Pew Hispanic Center, Nov. de 2003. Available at: <http://www.pewhispanic.org/files/reports/23.pdf>. Accessed on: 15 oct. 2015.

44 Por exemplo, o fluxo de transferência de dinheiro proveniente do exterior em El Salvador em 2002 foi de 15,1\% segundo o estudo do Pew Hispanic Center. REMITTANCE Senders and Receivers: tracking the transnational channels. Washington: Pew Hispanic Center, Nov. de 2003. Available at: <http://www.pewhispanic.org/ files/reports/23.pdf>. Accessed on: 15 oct. 2015.

45 BIZZOZERO, Lincoln; PASTORINO, Ana. Los Acuerdos Migratorios y de Circulación laboral en el ambito del Mercosur. Revista de Análise em Política Internacional, Brasília, v. 5, n. 1, p. 5-13, 2003. p. 10 . 
com as respectivas legislações internas. É reconhecido, também, o direito de acesso à educação em condições de igualdade com os cidadãos do País de recepção, independentemente da regularidade ou não da situação migratória dos genitores. Em outras palavras, o acesso ao sistema educacional público não pode ser negado ou limitado em razão da eventual clandestinidade dos pais. Em última análise, todavia, depreende-se que os direitos reservados aos filhos dos migrantes pelo Acordo do Mercosul não são mais do que a atuação de princípios de direitos humanos consagrados pelas convenções internacionais ${ }^{46}$. Nesse sentido, mesmo não sendo uma novidade em absoluto nem um privilégio para os sujeitos beneficiários, os Acordos confirmam a importância da proteção do indivíduos enquanto seres humanos e não apenas enquanto sujeito economicamente ativos, tutelando, em especial, os interesses dos menores.

Por fim, o art. 9, $\int 4^{\circ}$ refere-se às obrigações em matéria de previdência social, estabelecendo que os Estados-Partes examinarão a possibilidade de assinar acordos recíprocos neste âmbito. A ausência de conteúdo substancial desta disposição poderia ser totalmente superada com o simples reenvio ao Acordo Multilateral de Previdência Social de $1997^{47}$. Sem dúvida, perdeu-se a oportunidade de inserir as respectivas normas no novo Acordo ou de simplesmente fazer-lhe menção, mostrando, dessa forma, a coerência e o diálogo das normas emanadas no Mercosul. Além disso, o mesmo

46 Faz-se referência, por exemplo, à Declaração universal dos direitos do homem de 1948 e à Convenção internacional sobre os direitos da infância de 1989, ambas aprovadas pela Assembleia Geral das Nações Unidas.

47 MERCOSUL. Conselho do Mercado Comum. Decisão $n^{\circ}$ 19, de 15 de dezembro de 1997. Disponível em: <http://www.sice. oas.org/trade/mrcsrs/decisions/dec1997p.asp>. Acesso em: 15 dez. 2015. O Acordo reconhece os princípios materiais basilares do direito internacional em matéria de previdência social como a aplicação da lei do local da execução, a não discriminação, a conservação dos direitos adquiridos e a acumulação dos períodos de trabalho. Para aprofundamento ver: URIARTE, Ermida Oscar. La dimensión social del Mercosur. Montevideo: Fundación de Cultura Universitaria, 2004. Com relação à obrigação dos Estados-Partes de garantir a aplicação do princípio de não discriminação nessa matéria veja-se a jurisprudência argentina: Corte Suprema de Justicia de La Nación. Recurso de becho: A. 1023. XLIII, caso Alvarez, Maximiliano y otros c/ Cencosud S.A., de 7 de dezembro de 2010. ARGENTINA. Corte Suprema de Justicia de La Nación. Recurso de Hecho. Caso Alvarez, Maximiliano y otros c/ Cencosud S.A. Buenos Aires, de 7 de dezembro de 2010 Disponible en: <http://www.infojus.gob. ar/corte-suprema-justicia-nacion-federal-ciudad-autonoma-buenos-aires-alvarez-maximiliano-otros-cencosud-sa-accion-amparofa10000047-2010-12-07/123456789-740-0000-1ots-eupmocsollaf $>$. Visitado el: 15 oct. 2015. se conclui a partir da leitura atenta de outras disposições dos Acordos.

Analisando as demais disposições, pode-se igualmente observar que, apesar de o art. 2 fornecer a definição de alguns termos utilizados pelos Acordos (como "Estados-Parte", "Nacionais de uma Parte", "Imigrantes", "País de origem" e "País de recepção"), permanecem algumas imprecisões concernentes, por exemplo, à noção de "família" acolhida pelo Acordo, dado que os familiares dos cidadãos dos Estados Partes do Mercosul podem gozar dos mesmos direitos dos beneficiários primários, como previsto pelo art. $9, \S 2^{\circ}$, analisado precedentemente. Sob tal perspectiva, sobretudo em virtude da ambiguidade do termo "família", poderiam surgir problemas na medida em que não existe um órgão jurisdicional no âmbito mercosulino com competência para interpretar, na ocasião de uma eventual controvérsia, o conteúdo da condição de "familiar" de um nacional dos Estados Partes. Consequentemente, uma controvérsia deste gênero permaneceria submetida aos juízes nacionais que poderiam invocar a ordem pública nacional para limitar ou impedir o reagrupamento familiar garantido pelo Acordo, por exemplo, aos casais homoafetivos, considerando que não existe uniformidade da disciplina desta matéria nos ordenamentos jurídicos dos Estados Partes do Mercosullis.

\subsection{A criação de um espaço de livre residência no Mercosul}

De um modo geral, em relação ao conteúdo, alguns autores afirmam que esses Acordos introduziram um direito de residência, ou seja, uma "área de libre residencia"49, que é diferente de um pleno direito à livre circulação ${ }^{50}$

48 Em síntese, a Argentina e também o Uruguai e o Brasil (ambos a partir de 2013) reconhecem o direito ao matrimonio entre pessoas do mesmo sexo. O Equador e Colômbia permitem a união estável; por sua vez, o Paraguai, a Venezuela, a Bolívia, o Peru e o Chile não preveem nenhuma disciplina neste sentido. Dados disponíveis em: INTERNATIONAL LESBIAN, GAY, BISEXUAL, TRANS AND INTERESEX ASSOCIATION. Directorio LGBTI y organizaciones aliadas de ILGA. Available at: <http://ilga.org/ilga/en/ organisations/ILGA \%20LATIN\%20AMERICA $\% 20$ AND $\% 20$ CARIBBEAN>. Accessed on: 20 dec. 2014.

49 AGUIRRE, Orlando; MERA, Gabriela; NEJAMKIS, Lucila. Políticas migratorias e integración regional: la libre circulación y los desafíos a la ciudadanía. In: NOVICK, Susana (Dir.). Migraciones y Mercosur: una relación inconclusa. Buenos Aires: Catálogos, 2010. p. 50-72. p. 65.

50 VARELA, Justo Corti. Evolución de la libre circulación de personas en el Mercosur y su impacto en las políticas migratorias 
dos nacionais dos Estados-Partes. De fato, o art. 8, $\$ 1^{\circ}$ é claro ao afirmar que as pessoas que tenham obtido a residência "têm direito a entrar, sair, circular e permanecer livremente no território do país de recepção". Os Acordos, portanto, circunscrevem a aplicação e a eficácia do direito à livre circulação em um contexto estritamente "bilateral", ou seja, apenas entre o País de origem e o de recepção ${ }^{51}$. Nesses termos, efetivamente, eles não contemplam um real direito de livre circulação no território do Mercosul, mas sim um direito de residência, garantido diante da satisfação dos requisitos previstos pelos Acordos.

Com relação à residência, os Acordos preveem a concessão de dois tipos de permissão. A primeira é a "residência temporária" que, dependendo do caso, pode durar até dois anos, podendo ela ser convertida em "residência permanente", desde que o interessado efetue a solicitação dentro de noventa dias antes do vencimento da mesma. Se a pessoa não requerer a conversão e permanecer no país de recepção, o art. 6 determina que esta fica submetida à legislação migratória interna de cada Estado Parte.

Os requisitos para a concessão da residência temporária estão elencados no art. 4 dos Acordos, o qual prevê que o solicitante deve apresentar a seguinte documentação: passaporte válido, carteira de identidade ou certidão de nacionalidade; certidão de nascimento, prova do estado civil e certidão de naturalização quando for o caso; certidão negativa de antecedentes judiciais e/ou penais e/ou policiais dos últimos cinco anos; autodeclaração de ausência de antecedentes internacionais penais ou policiais; pagamento de uma taxa de serviço e um certificado médico que ateste a aptidão psicofísica do peticionante se assim exigido pela legislação interna do Estado Parte.

Atenção especial suscita a última das condições previstas no art. 4, letra "f $f$ ", segundo a qual o peticionante

nacionales. In: GOIZUETA VÉRTIZ, Juana; GÓMEZ FERNÁNDEZ, Itziar; PASCUAL GONZÁLEZ, María Isabel. La libre círculación de personas en los sistemas de integración económica: modelos comparados: Unión Europea, Mercosur y Comunidad Andina. Navarra: Thomson Reuters Aranzadi, 2012. p. 104-118. p. 151.

51 SALZMANN, Antonio Cardesa. El contenido jurídico de la libre circulación de personas en el Mercosur: balance y perspectivas. In: GOIZUETA VÉRTIZ, Juana; GÓMEZ FERNÁNDEZ, Itziar; PASCUAL GONZÁLEZ, María Isabel. La libre círculación de personas en los sistemas de integración económica: modelos comparados: Unión Europea, Mercosur y Comunidad Andina. Navarra: Thomson Reuters Aranzadi, 2012. p. 163-185. p. 166. deve apresentar um certificado médico acerca da sua "capacidade psicofísica" se assim exigido pela legislação interna do Estado-Parte de ingresso. De fato, "no resulta claro el objetivo perseguido al introducir una disposición de esta indole en un instrumento internacional que tiene por finalidad el facilitar la obtención de residencia." ${ }^{52}$. De qualquer forma, a necessidade da observância dos citados requisitos para obtenção da residência, além daquele relativo à titularidade da nacionalidade de um dos Estados Partes, é confirmada pela jurisprudência estatal ${ }^{53}$.

Com a finalidade de efetuar a conversão em residência permanente, o art. 5 exige que o interessado apresente os seguintes documentos: certidão de residência temporária; passaporte válido e vigente ou carteira de identidade; certidão negativa de antecedentes judiciais e/ou penais e/ou policiais, no país de recepção; comprovação dos meios de vida lícitos que permitam a subsistência do peticionante e de seus familiares; pagamento de uma taxa. Nota-se, portanto, que apenas para a concessão da residência permanente (após dois anos) é que as autoridades migratórias poderão exigir um comprovante de renda do peticionante. De modo diametralmente oposto, salienta-se que o cidadão da União Europeia que queira gozar do direito de residência em outro Estado-membro por um período superior a três meses deve comprovar, desde o início, a possibilidade de dispor, para si próprio e para a sua família, de recursos financeiros suficientes para a sua subsistência ${ }^{54}$.

Diante do exposto, resta evidente que os Acordos constituem respostas necessárias à determinadas situações de fato e demonstram também a capacidade do Mercosul de definir as suas políticas no âmbito político e social. Por outro lado, é inegável a presença de algumas questões críticas, tais como as circunstâncias em que

52 BIZZOZERO, Lincoln; PASTORINO, Ana. Los Acuerdos Migratorios y de Circulación laboral en el ambito del Mercosur. Revista de Análise em Política Internacional, Brasília, v. 5, n. 1, p. 5-13, 2003. p. 8.

53 BRASIL. Tribunal Regional Federal (1 Região). Embargos de Declaração em Agravo Regimental em Agravo de Instrumento EDAGA 25896 MG 2008.01.00.025896-0. Quinta Turma. Relator: Des. Federal João Batista Moreira. Brasília, 06 de maio de 2009. Disponível em: <http://trf-1.jusbrasil.com.br/jurisprudencia/4126664/embargos-de-declaracao-no-agravo-regimental-no-agedaga-25896-mg-20080100025896-0\#>. Acesso em: 15 dez. 2015. 54 Art. 7 da Diretiva 2004/38/CE. CONSELHO DA UNIÃO EUROPEIA. Directiva n. 38, de 29 de abril de 2004. Jornal Oficial da União Europeia, Bruxelas, 30 abr. 2004. Disponível em: <http:// eur-lex.europa.eu/LexUriServ/LexUriServ.do?uri=OJ:L:2004:158:0 077:0123:pt:PDF>. Acesso em: 15 dez. 2015. 
foram elaborados. Todo procedimento de preparação dos Acordos foi confiado, exclusivamente, aos Ministro de Interior. Tal escolha não se coaduna com aspectos técnicos ao considerar que os órgãos e as instituições com competência específica na matéria não foram convidados a participar dos trabalhos preparatórios. Além disso, mostra-se discutível a escolha de não adotar um instrumento orgânico em matéria de migração e circulação de pessoas, capaz de uniformizar e tornar coerente todo o sistema ${ }^{55}$.

Apesar disso, não se pode negar que se trate de instrumentos jurídicos que sinalizam o início de um percurso para a criação de um regime comum em matéria de migração e de residência no espaço mercosulino. Sob tal ponto de vista, os Acordos se apresentam como o passo mais concreto e relevante tomado até hoje em direção a uma efetiva zona de liberdade de circulação e residência das pessoas no espaço de integração regional do Mercosul.

De uma análise das sucessivas Decisões em tema de vistos adotadas pelo Conselho Mercado Comum nos últimos anos ${ }^{56}$, restam claras as dificuldades encontradas no processo de realização de uma completa liberdade de circulação de pessoas, dado que nenhuma delas foi efetivamente colocada em prática. Por estas e pelas razões já expostas, é que realmente parece estarmos

55 BIZZOZERO, Lincoln; PASTORINO, Ana. Los Acuerdos Migratorios y de Circulación laboral en el ambito del Mercosur. Revista de Análise em Política Internacional, Brasília, v. 5, n. 1, p. 5-13, 2003. p. 11.

56 MERCOSUL. Conselho do Mercado Comum. Decisão $n^{\circ} 16$, de 15 de dezembro de 2003. Disponível em: < http://www.camara. gov.br/sileg/integras/428260.pdf>. Acesso em: 15 dez. 2015. sobre a criação do "Visto Mercosul"; MERCOSUL. Conselho do Mercado Comum. Decisão $n^{\circ}$ 10, de 20 de julho de 2006. Disponível em: $\quad<$ http://gd.mercosur.int/SAM\%5CGestDoc\%5Cpubweb. nsf/EE4C0C2AEBD99F1503257F1D00536141/\$File/DEC_0102006_PT_AcdoPrazo90DiasTuristasNacionais.pdf>. Acesso em: 15 dez. 2015. para a concessão de uma estadia de 90 dias aos turistas, cidadãos dos Estados-Partes do Mercosul e dos Estados Associados; MERCOSUL. Conselho do Mercado Comum. Decisão $n^{\circ}$ 21, de 20 de julho de 2006. Disponível em: <http://gd.mercosur. int/SAM\%5CGestDoc\%5Cpubweb.nsf/E3D6470E4AD8BD960 3257F1D00536502/\$File/DEC_021-2006_PT_FERR_AcdGratuidade $\% 20 \mathrm{de} \% 20$ Vistos.pdf $>$. Acesso em: 15 dez. 2015. sobre a gratuidade dos vistos para os estudantes e os docentes dos Estados Partes do Mercosul; MERCOSUL. Conselho do Mercado Comum. Decisão $n^{\circ}$ 53, de 16 de dezembro de 2010. Disponível em: <http:// gd.mercosur.int/SAM $\% 5$ CGestDoc $\% 5 C$ pubweb.nsf/4D7F0F7 FF4DF5FBD03257F1D0053868C/\$File/DEC_053-2010_PT_ FERR_Patente\%20MERCOSUL.pdf $>$. Acesso em: 15 dez. 2015. Salienta-se, todavia, que nenhuma destas Decisões são atualmente em vigor, em razão da falta de ratificação por alguns Estados Partes. mais próximos da consolidação de um espaço de livre residência. De qualquer modo, vale ressaltar que constituem evidentes obstáculos ao desenvolvimento do Mercosul a facilidade com que se adotam tais Decisões, a burocracia e a lentidão dos Parlamentos nacionais na sua incorporação, assim como o excesso de poder decisório nas mãos dos Estados.

Tais fatores freiam a plena realização da livre circulação dos cidadãos na região e impedem que esta se torne uma prática comum como já ocorre em outros fenômenos integracionistas ${ }^{57}$. Por tais razões, segundo alguns autores, a livre circulação nos processos de integração latino-americanos - em particular, no Mercosul - não alcançaram o nível necessário para poder configurar um estatuto de cidadão comunitário, meta que, ao contrário, foi alcançada no âmbito europeu ${ }^{58}$. Apesar disso, não restam dúvidas que o êxito do fenômeno de integração do Mercosul, mesmo sob o aspecto econômico, deva passar, inevitavelmente, pelo envolvimento dos cidadãos. Não se pode olvidar que, muito embora o Mercosul atualmente seja uma união aduaneira "imperfeita", o objetivo final do Tratado de Assunção é o aperfeiçoamento de um mercado comum. E, por sua vez, o mercado comum, enquanto fase da integração econômica, pressupõe a completa realização da livre circulação dos quatro fatores de produção: bens, serviços, capitais e pessoas.

Considerando as fontes normativas do Mercosul e, em particular, o direito derivado, observa-se que os Estados-Partes continuam a criar, gradualmente, substrato jurídico comum aparentemente capaz de abrir as portas para futuros desenvolvimentos no campo da livre circulação e residência das pessoas na região. O núcleo central seria constituído pelo reconhecimento do direito de residência e de acesso às atividades econômicas em condições paritárias com os cidadãos do Estado-membro de residência ${ }^{59}$.

57 CAMARGO, Sonia. O processo de integração regional: fronteiras abertas para os trabalhadores do Mercosul. Contexto Internacional, Rio de Janeiro, v. 32, n. 2, p. 489-517, jul./dez. 2010. p. 492.

58 GOIZUETA VÉRTIZ, Juana; GÓMEZ FERNÁNDEZ, Itziar; PASCUAL GONZÁLEZ, María Isabel. La libre círculación de personas en los sistemas de integración económica: modelos comparados: Unión Europea, Mercosur y Comunidad Andina. Navarra: Thomson Reuters Aranzadi, 2012. p. 21.

59 SALZMANN, Antonio Cardesa. El contenido jurídico de la libre circulación de personas en el Mercosur: balance y perspectivas. In: GOIZUETA VÉRTIZ, Juana; GÓMEZ FERNÁNDEZ, Itziar; PASCUAL GONZÁLEZ, María Isabel. La libre círculación de personas en los sistemas de integración económica: modelos comparados: Unión Eu- 
Insere-se em tal tendência, e ao mesmo tempo demonstra a atualidade desse tema, a recente proposta de modificação da lei sobre a imigração uruguaia ${ }^{60}$ no sentido de passar a prever a concessão da residência permanente a todos os cidadãos dos Estados Partes do Mercosul. O único requisito solicitado é a demonstração da titularidade da cidadania de um destes países. $\mathrm{Na}$ exposição de motivos, afirma-se que o projeto reflete a "vocación integracionista" do Uruguai e "se enmarca en una política migratoria basada en una perspectiva de derechos y en linea con los compromisos internacionales asumidos", dentre os quais o Acordo sobre Residência assinado em 2002 no âmbito do Mercosul, expressamente citado pelo projeto de lei. Enfim, o ato salienta ainda uma vez a intenção de reforçar e aprofundar o processo de integração por meio da implementação de uma política de livre circulação das pessoas pertencentes à região.

Apesar das dificuldades apontadas, não se pode negar um certo otimismo diante da adoção de importantes medidas destinadas, principalmente, à harmonização das normativas neste setor ${ }^{61}$. Observa-se, ademais, que a problemática migratória e o conceito de livre circulação e residência têm ganhado espaço no debate político. De fato, alguns autores sustentam que a noção restritiva de migração está gradualmente deixando espaço a uma ideia de cidadania comunitária ou regional ${ }^{62}$.

Desse modo, a entrada em vigor dos Acordos sobre Residência não são um ponto de chegada, mas antes uma porta aberta para as futuras iniciativas de integra-

ropea, Mercosur y Comunidad Andina. Navarra: Thomson Reuters Aranzadi, 2012. p. 163-185. p. 173-179.

60 Proposta n. 215074 do Ministro das Relações Exteriores do Uruguai sobre o Projeto de lei encaminhado ao Parlamento em 24 de janeiro de 2014 que propõe a modificação da lei uruguaia sobre imigração n. 18.250 de 6 de janeiro de 2008. Atualmente aguarda a provação pelos parlamentares.

61 GOIZUETA VÉRTIZ, Juana; GÓMEZ FERNÁNDEZ, Itziar; PASCUAL GONZÁLEZ, María Isabel. La libre círculación de personas en los sistemas de integración económica: modelos comparados: Unión Europea, Mercosur y Comunidad Andina. Navarra: Thomson Reuters Aranzadi, 2012. p. 17-19. De fato, os autores alegam que o distanciamento habitual entre a realidade e a norma, entre a facilidade com que se tomam decisões ambiciosas e os obstáculos para aplicar as normas, obriga a ter uma atitude muito prudente a fim de avaliar o presente e impedem de fazer previsões confiáveis para o futuro da livre circulação das pessoas no Mercosul e também na Comunidade Andina.

62 AGUIRRE, Orlando; MERA, Gabriela; NEJAMKIS, Lucila. Políticas migratorias e integración regional: la libre circulación y los desafíos a la ciudadanía. In: NOVICK, Susana (Dir.). Migraciones y Mercosur: una relación inconclusa. Buenos Aires: Catálogos: 2010. p. $50-72$. p. 68. ção da região ${ }^{63}$. Nesta mesma linha de desenvolvimento insere-se o Estatuto da Cidadania do Mercosul, um Plano de Ação adotado no final de 2010, que objetiva delinear uma nova perspectiva para o Mercosul "Social". Trata-se de um cronograma de ações que deve ser adotado a fim de estabelecer direitos mínimos, em diversos âmbitos, aos nacionais dos Estados Partes que, por sua vez, passariam a ser denominados "cidadãos do Mercosul". Ressalta-se que a análise de tal Estatuto será realizada em outro artigo destinado exclusivamente para tal fim.

\section{Considerações finais}

O direito à livre residência mostra-se como uma importante medida adotada no sentido de assegurar aos nacionais e aos familiares destes o direito de residir no território do Mercosul mediante a observância de procedimento simplificado e que procura facilitar a regularização migratória dos indivíduos que se encontrem em situação vulnerável. Trata-se de um relevante avanço tanto do ponto de vista do conteúdo substancial dos Acordos sobre Residência quanto da extensão dos sujeitos beneficiados. Conforme repetidamente salientado, não existe, ainda, uma efetiva liberdade de circulação de pessoas na região, uma vez que persistem os controles migratórios efetuados nas fronteiras estatais.

Paradoxalmente, porém, já é possível vislumbrar um direito à livre residência no âmbito do Mercosul, no qual os cidadãos dos dez Estados Partes possuem direitos e prerrogativas diferenciadas em comparação com os indivíduos provenientes de países terceiros. A facilidade para a concessão da residência provisória e permanente aos cidadãos mercosulinos que migram para outro Estado da região revela-se uma ferramenta jurídica fundamental à garantia dos direitos fundamentais destes indivíduos e, sem dúvida, sinaliza a consolidação de um primeiro acervo normativo em prol dos nacionais dos Estados-Partes do Mercosul, o qual toca mais de perto questões sensíveis do dia a dia da população.

63 SALZMANN, Antonio Cardesa. El contenido jurídico de la libre circulación de personas en el Mercosur: balance y perspectivas. In: GOIZUETA VÉRTIZ, Juana; GÓMEZ FERNÁNDEZ, Itziar; PASCUAL GONZÁLEZ, María Isabel. La libre círculación de personas en los sistemas de integración económica: modelos comparados: Unión Europea, Mercosur y Comunidad Andina. Navarra: Thomson Reuters Aranzadi, 2012. p. 163-185. p. 165. 
Unir os povos em favor de uma dimensão social que ultrapasse o aspecto puramente econômico apresenta-se como um dos escopos emergentes dos vários Países reunidos através do vínculo de um tratado internacional de integração. Os Acordos sobre Migração e Residência inserem-se, portanto, em quadro mais amplo de harmonização de políticas comuns voltadas ao estabelecimento de parâmetros mínimos de tratamento dos cidadãos dos Estados-Partes do Mercosul e de seus familiares, indicando relevante passo rumo à consolidação de um bloco regional mais consciente da sua verdadeira dimensão teleológica de integração.

\section{REFERÊNCIAS}

ABRAMOVICH,Victor. Direitos humanos no marco do processo de integração regional no Mercosul. Revista de la Secretaría del Tribunal Permanente de Revisión, Asuncion, v. 1, n. 2, p. 351-361, 2013.

ACCIOLY, Elizabeth. O Atual mecanismo de solução de controvérsias do Mercosul: o Protocolo de Olivos. Revista da Faculdade de Direito, Lisboa, v. 45, n. 13, p. 204226, Jan. 2004.

AGUIRRE, Orlando; MERA, Gabriela; NEJAMKIS, Lucila. Políticas migratorias e integración regional: la libre circulación y los desafíos a la ciudadanía. In: NOVICK, Susana (Dir.). Migraciones y Mercosur: una relación inconclusa. Buenos Aires: Catálogos, 2010. p. 50-72.

ALEXOVIČOVÁ, Iveta. The right of citizenship of the Union and their family members to move and reside freely within the territory of the Member States. In: SCHNEIDER, Hildegard. Migration, Integration and Citizenship: a challenge for Europe's future. Maastricht: Forum Maastricht, 2005. p. 73-105.

ARGENTINA. Corte Suprema de Justicia de La Nación. Recurso de Hecho. Caso Alvarez, Maximiliano y otros c/ Cencosud S.A. Buenos Aires, de 7 de dezembro de 2010. Disponible en: <http://www.infojus.gob.ar/ corte-suprema-justicia-nacion-federal-ciudad-autonoma-buenos-aires-alvarez-maximiliano-otros-cencosud-sa-accion-amparo-fa10000047-2010-12-07/123456789-740-0000-1ots-eupmocsollaf $>$. Visitado el: 15 oct. 2015.
ARIETI, Samuel A. Development: the Role of Mercosur as a Vehicle for Latin American Integration. Chicago Journal of International Law, Chigado, v. 6, n. 2, p. 761773, Jan. 2006.

BIZZOZERO, Lincoln; PASTORINO, Ana. Los Acuerdos Migratorios y de Circulación laboral en el ambito del Mercosur. Revista de Análise em Política Internacional, Brasília, v. 5, n. 1, p. 5-13, 2003.

BRASIL. Câmara dos Deputados. Constituições dos paises do Mercosul, 1996-2000: textos constitucionais Argentina, Bolívia, Brasil, Chile, Paraguai e Uruguai. Brasília: Câmara dos Deputados, 2001. Disponível em: < http:/ / www.planalto.gov.br/ccivil_03/Constituicao/Constituicao.htm>. Acesso em: 15 dez. 2015.

BRASIL. Decreto $n^{0}$ 1.901, de 09 de maio de 1996. Disponível em: <http://www.planalto.gov.br/ccivil_03/ decreto/D1901.htm>. Acesso em: 15 dez. 2015.

BRASIL. Decreto $n^{0}$ 6.975, de 7 de outubro de 2009. Disponível em: < http://www.planalto.gov.br/ccivil_03/_ Ato2007-2010/2009/Decreto/D6975.htm>. Acesso em: 15 dez. 2015.

BRASIL. Tribunal Regional Federal (1 Região). Embargos de Declaração em Agravo Regimental em Agravo de Instrumento EDAGA 25896 MG 2008.01.00.025896-0. Quinta Turma. Relator: Des. Federal João Batista Moreira. Brasília, 06 de maio de 2009. Disponível em: < http:/ / trf-1.jusbrasil.com.br/jurisprudencia/4126664/embargos-de-declaracao-no-agravo-regimental-no-ag-edaga25896-mg-20080100025896-0\#>. Acesso em: 15 dez. 2015.

CAMARGO, Sonia. O processo de integração regional: fronteiras abertas para os trabalhadores do Mercosul. Contexto Internacional, Rio de Janeiro, v. 32, n. 2, p. 489517, jul./dez. 2010.

CONDINANZI, Massimo; LANG, Alessandra; NASCIMBENE, Bruno. Cittadinanza dell'Unione e libera circolaz̧ione delle persone. 2. ed. Milano: Giuffrè, 2006.

CONSELHO DA UNIÃO EUROPEIA. Directiva n. 38, de 29 de abril de 2004. Jornal Oficial da União Europeia, Bruxelas, 30 abr. 2004. Disponível em: < http://eurlex.europa.eu/LexUriServ/LexUriServ.do?uri=OJ:L:20 04:158:0077:0123:pt:PDF>. Acesso em: 15 dez. 2015.

FLÔRES JUNIOR, Renato G. Símbolos e integrações regionais: uma breve introdução com vistas ao Mercosul. In: HOFMEISTER, Wilhelm. União Europeia e Mer- 
cosul: dois momentos especiais da integração regional. Rio de Janeiro: Fundação Konrad Adenauer no Brasil, abr. 2007. (Cadernos Adenauer, 1). p. 17-31.

FONTOURA, Jorge. A revisão institucional do Mercosul: Ouro Preto II. Revista de Estudos Europeus, Coimbra, v. 1, n. 1, p. 291-297, jan./jun. 2007.

GOIZUETA VÉRTIZ, Juana; GÓMEZ FERNÁNDEZ, Itziar; PASCUAL GONZÁLEZ, María Isabel. La libre círculación de personas en los sistemas de integración económica: modelos comparados: Unión Europea, Mercosur y Comunidad Andina. Navarra: Thomson Reuters Aranzadi, 2012.

KEGEL, Patrícia Luíza; AMAL, Mohamed. Instituições, direito e soberania: a efetividade jurídica nos processos de integração regional nos exemplos da União Europeia e do Mercosul. Revista Brasileira de Política Internacional, Brasília, v. 52, n. 1, p. 53-70, jan./jun. 2009.

MÁRMORA, Lelio; PÉREZ, Vichich Nora. Elementos de politicas migratorias para el Mercosur: Informe Nacional de Desarrollo Humano. Buenos Aires: Senado de la Nación Argentina, 1997.

MERCOSUL. Conselho do Mercado Comum. Acordo sobre residência para nacionais dos estados partes do Mercosul, Bolivia e Chile. Disponível em: <http://www.mercosur. int/innovaportal/file/5838/1/56-acuerdoresidenciamsur-boliviaychile.pdf>. Acesso em: 15 dez. 2015.

MERCOSUL. Conselho do Mercado Comum. Decisão $n^{\circ}$ 05, de 22 de abril de 1993. Disponível em: <http:// gd.mercosur.int/SAM/GestDoc/PubWeb.nsf/ OpenFile?OpenAgent\&base $=\mathrm{SAM} \backslash$ GestDoc $\backslash$ DocOfic0Arch.nsf\&id =832579C 700726F0D832577810052E 8A2\&archivo=RES_005_1993-PT_Comiss $\%$ F5es $\% 20$ SGTs $\% 20 \mathrm{~N} \%$ B0\%202,\%207,\%2010.doc>. Acesso em: 15 dez. 2015.

MERCOSUL. Conselho do Mercado Comum. Decisão $n^{\circ}$ 07, de 29 de junho de 2012. Disponível em: <http:// gd.mercosur.int/SAM\%5CGestDoc\%5Cpubweb. nsf/A2829874C636D36B03257F1D0049FB6C/\$Fi le/DEC_007-2012_PT_Complementacao\%20Acordo $\% 20$ Recife $\% 20$ Materia $\% 20$ Migratoria.pdf $>$. Acesso em: 15 dez. 2015.

MERCOSUL. Conselho do Mercado Comum. Decisão $n^{\circ}$ 10, de 20 de julho de 2006. Disponível em: <http:// gd.mercosur.int/SAM $\% 5$ CGestDoc $\% 5$ Cpubweb.nsf/ EE4C0C2AEBD99F1503257F1D00536141/\$File/
DEC_010-2006_PT_AcdoPrazo90Dias'TuristasNacionais.pdf>. Acesso em: 15 dez. 2015.

MERCOSUL. Conselho do Mercado Comum. Decisão $n^{\circ}$ 12, de 17 de dezembro de 1991. Disponível em: <http:/ / www.mercosur.int/msweb/portal\%20intermediario/ Normas/normas_web/Decisiones/PT/CMC_1991_ DEC_012_PT_TransitCiudada.PDF $>$. Acesso em: 15 dez. 2015.

MERCOSUL. Conselho do Mercado Comum. Decisão $n^{\circ}$ 13, de 5 de julho de 2002. Disponível em: <http:// www.mercosur.int/msweb/Normas/normas_web/ Decisiones/PT/Dec_013_002_Acordo\%20Antidumping\%200MC_Ata\%201_02.PDF>. Acesso em: 15 dez. 2015.

MERCOSUL. Conselho do Mercado Comum. Decisão $n^{\circ}$ 14, de 29 de junho de 2000. Disponível em: < http:/ / gd.mercosur.int/SAM\%5CGestDoc\%5Cpubweb. $\mathrm{nsf} / \mathrm{AA} 30 \mathrm{EDC}$ D 55 AF 15 D03257 F 1 D 0049 0651/\$File/DEC_014-2000_PT_Regul\%20 Reg $\% 20 \operatorname{Tr} \%$ C 6\%92n sito $\% 20 \mathrm{Vicina} 1 \% 20$ Fronteiri\%E2\%80\%A1o_Ata\%201_00.pdf>. Acesso em: 15 dez. 2015 .

MERCOSUL. Conselho do Mercado Comum. Decisão $n^{\circ}$ 14, de 5 de julho de 2002. Disponível em: <http:// www.sice.oas.org/trade/mrcsrs/decisions/dec1402p. asp>. Acesso em: 15 dez. 2015.

MERCOSUL. Conselho do Mercado Comum. Decisão $n^{\circ}$ 15, de 29 de junho de 2000. Disponível em: <http:/ / gd.mercosur.int/SAM $\% 5$ CGestDoc $\% 5$ Cpubweb.nsf/ C53D5201470B3A1503257F1D0049314D/\$File/ DEC_015-2000_PT_Reg\%20Tr\%C6\%92nsito\%20 Vicin $\% 20$ Front $\% 20$ MCS $\% 20 B o l \% 20$ Chile_Ata $\% 20$ 1_00.pdf>. Acesso em: 15 dez. 2015.

MERCOSUL. Conselho do Mercado Comum. Decisão $n^{\circ}$ 16, de 15 de dezembro de 2003. Disponível em: < http:/ / www.camara.gov.br/sileg/integras/428260.pdf $>$. Acesso em: 15 dez. 2015.

MERCOSUL. Conselho do Mercado Comum. Decisão $n^{\circ} 18$, de 07 de dezembro de 1999. Disponível em: < http:/ / www.mercosur.int/msweb/Normas/normas_web/ Decisiones/PT/Dec_018_099_Tr\%C3\%A2nsito $\% 20$ Vicinal $\% 20$ Fronteiri $\%$ C3\%A7o\%20MCS_Ata $\% 20$ 2_99.PDF>. Acesso em: 15 dez. 2015.

MERCOSUL. Conselho do Mercado Comum. Decisão $n^{\circ}$ 19, de 07 de dezembro de 1999. Disponível em: 
<http://www.mercosur.int/msweb/portal\%20intermediario/Normas/normas_web/Decisiones/PT/ Dec_019_099_Tr\%C3\%A2nsito $\% 20$ Vicinal $\% 20$ Front $\% 20 \mathrm{MCS} \% 20 \mathrm{Bol} \% 20 \mathrm{Chile} \_$Ata $\% 202 \_99 . P D F>$. Acesso em: 15 dez. 2015.

MERCOSUL. Conselho do Mercado Comum. Decisão $n^{\circ}$ 19, de 15 de dezembro de 1997. Disponível em: <http:// www.sice.oas.org/trade/mrcsrs/decisions/dec1997p. asp>. Acesso em: 15 dez. 2015.

MERCOSUL. Conselho do Mercado Comum. Decisão $n^{\circ}$ 20, de 29 de junho 2012. Disponível em: <http:// www.cartillaciudadania.mercosur.int/uploads / DEC_020-2012_PT_Adesao $\% 20 \mathrm{Col} \% 20$ Acordo $\% 20$ Resid\%C3\%AAncia.pdf>. Acesso em: 15 dez. 2015.

MERCOSUL. Conselho do Mercado Comum. Decisão $n^{\circ} 21$, de 20 de julbo de 2006. Disponível em: <http:// gd.mercosur.int/SAM\%5CGestDoc\%5Cpubweb. nsf/E3D6470E4AD8BD9603257F1D00536502/\$F ile/DEC_021-2006_PT_FERR_AcdGratuidade $\% 20$ de\%20Vistos.pdf>. Acesso em: 15 dez. 2015.

MERCOSUL. Conselho do Mercado Comum. Decisão $n^{\circ}$ 21, de 28 de junho 2011. Disponível em: <http:// gd.mercosur.int/SAM\%5CGestDoc\%5Cpubweb.ns f/852556C938D1A7D703257F1D004C7D16/\$Fi le/DEC_021-2011_PT_Ades\%C3\%86o\%20Equador $\% 20$ Residen $\% 20$ Nacionais.pdf $>$. Acesso em: 15 dez. 2015.

MERCOSUL. Conselho do Mercado Comum. Decisão n 4, de 28 de junho 2011. Disponível em: <http:// gd.mercosur.int/SAM\%5CGestDoc\%5Cpubweb.nsf/ E1B5E57FB6D43E1F03257F1D004C3DCB/\$File/ DEC_004-2011_PT_Ades\%C3\%86o\%20Peru $\% 20$ Acordo\%20Residen\%20Nacionais.pdf $>$. Acesso em: 15 dez. 2015.

MERCOSUl. Conselho do Mercado Comum. Decisão $n^{\circ} 48$, de 14 de dezembro de 2000. Disponível em: <http:// gd.mercosur.int/SAM\%5CGestDoc\%5Cpubweb. nsf/ 6420A63D340570CA03257F1D004AF9BF /\$File/DEC_048-2000_PT_FERR_Acordo\%20 Isen $\% \mathrm{E} 2 \% 80 \% \mathrm{~A} 1 \% \mathrm{C} 3 \% 860 \% 20 \mathrm{de} \% 20 \mathrm{Vistos}$ Ata\%202_00.pdf>. Acesso em: 15 dez. 2015.

MERCOSUL. Conselho do Mercado Comum. Decisão $n^{\circ} 48$, de 6 de dezembro de 2002. Disponível em: <http:/ / www.sice.oas.org/trade/mrcsrs/decisions/dec2802p. asp>. Acesso em: 15 dez. 2015.

MERCOSUL. Conselho do Mercado Comum. Decisão n 53, de 16 de dezembro de 2010. Disponível em: <http:/ / gd.mercosur.int/SAM\%5CGestDoc\%5Cpubweb.nsf /4D7F0F7FF4DF5FBD03257F1D0053868C/\$File/ DEC_053-2010_PT_FERR_Patente\%20MERCOSUL.pdf $>$. Acesso em: 15 dez. 2015.

MERCOSUL. Conselho do Mercado Comum. Decisão $n^{\circ}$ 9, de 5 de outubro de 1995. Disponível em: <http:// gd.mercosur.int/SAM/GestDoc/PubWeb.nsf/ OpenFile?OpenAgent\&base $=\mathrm{SAM} \backslash$ GestDoc $\backslash$ DocOfic0Arch.nsf\&id =832579C700726F0D 83257751 006F6800\&archivo=DEC_008-1995_PT_Prot $\% 20$ Harm \%20Norm\%20Intelect $\% 20$ Proc $\% 20$ Denom $\% 20$ Origem_Ata\%201_95.doc>. Acesso em: 15 dez. 2015.

MERCOSUL. Declaração Sociolaboral do Mercosul. Disponível em: <http://www.dhnet.org.br/direitos/ deconu/a_pdf/dec_sociolaboral_mercosul.pdf $>$. Acesso em: 15 dez. 2015.

MERCOSUL. Grupo Mercado Comum. Resolução n 38 , de 30 de junho de 1993. Disponível em: <http://www2. uol.com.br/actasoft/actamercosul/novo/res_44_94. htm>. Acesso em: 15 dez. 2015.

MERCOSUL. Grupo Mercado Comum. Resolução n 40, de 8 de dezembro de 1998. Disponível em: <http://www. mercosur.int/innovaportal/v/387/4/innova.front/busqueda-de-normativa >. Acesso em: 15 dez. 2015.

MERCOSUL. Grupo Mercado Comum. Resolução n 44 , de 03 de agosto de 1994. Disponível em: <http://www. mercosur.int/msweb/Normas/normas_web/Resoluciones/PT/GMC_RES_1993-038_PT_Grupo_AD_ HOC_Documento_\%C3\%9Anico_Viagem.PDF $>$. Acesso em: 15 dez. 2015.

MERCOSUL. Grupo Mercado Comum. Resolução $n^{\circ}$ 59, de 21 de junho de 1996. Disponível em: <http:// gd.mercosur.int/SAM/GestDoc/PubWeb.nsf/ OpenFile?OpenAgent\&base $=\mathrm{SAM} \backslash \mathrm{GestDoc} \backslash$ DocOfic0Arch.nsf\&id=832579C700726F0D832577590057 CCDC\&archivo=RES_059-1996_PT_Cria\%E7\%E3 oCentrosConsulDocuPersonales.doc $>$. Acesso em: 15 dez. 2015 .

MODOLO, Vanina. La movilidad territorial en el Mercado Común Europeo y Mercosureño. In: NOVICK, Susana (Dir.). Migraciones y Mercosur. una relación incon- 
clusa. Buenos Aires: Catálogos: 2010. p. 29-50.

MONNET, Jean. Memórias: a construção da Unidade Européia. Brasilia: EdUnB, 1986.

NASCIMBENE, Bruno. Le droit de la nationalité et le droit des organisations d'intégration régionales. Vers de nowveaux statuts de résidents? Leiden: Brill, 2014. (Recueil des Cours de l'Académie de La Haye, 367).

NASCIMBENE, Bruno; ROSSI DAL POZZO, Francesco. Diritti di cittadinanza e libertà di circolazione nell'Unione europea. Padova: CEDAM, 2012.

NOVICK, Susana (Dir.). Introdución, migraciones, políticas e integración regional: avances y desafíos. In:_. Migraciones y Mercosur: una relación inconclusa. Buenos Aires: Catálogos, 2010. p. 9-28.

NUNES, Maria do Rosário. Após morte de Brayan, ministra vai debater situação de bolivianos no país. Folha de São Paulo. São Paulo, 1 jul. 2013. Disponível em: < http:/ / www1.folha.uol.com.br/cotidiano/2013/07/1304235apos-morte-de-brayan-ministra-vai-debater-situacaode-bolivianos-no-pais.shtml>. Acesso em: 10 out. 2013

PAGANO, Emmanuele. Ricongiungimento familiare, cittadinanza e residenza: dal caso Zambrano al caso Dereci. Diritto comunitario e degli scambi internazionali, v. 51, n. 3, p. 467-475, 2012.

PATRIOTA, Antônio. Para Patriota, o objetivo é estabelecer uma efetiva cidadania mercosulina. Brasília, MRE, 2011. Entrevista ao Boletim em Questão, em 26 de março de 2011. Disponível em: <http://www.itamaraty.gov. $\mathrm{br} /$ index.php?option $=$ com_content\&view $=$ article $\&$ $\mathrm{id}=4588$ :para-patriota-o-objetivo-e-estabelecer-umaefetiva-cidadania-mercosulina-em-questao-secom-pr26-3-2011\&catid $=195 \&$ Itemid $=455 \&$ lang $=$ pt $-B R>$. Acesso em: 15 ago. 2014.

PORTUGAL. Comissão de Assuntos Europeus da Assembleia da República. Tratado de Lisboa: versão consolidada. Disponível em: < https://www.parlamento.pt/europa/Documents/Tratado_Versao_Consolidada.pdf $>$. Acesso em: 15 dez. 2015.

QUEIROLO, Ilaria; SCHIANO DI PEPE, Lorenzo. Lezioni di diritto dell'Unione europea e relazioni familiari. 2. ed. Torino: Giappichelli, 2010.

QUINTÃO, Aylê-Salassié Filgueiras. Americanidade: Mercosul, passaporte para a integração. Brasília: Congresso Federal, 2010.
REMITTANCE Senders and Receivers: tracking the transnational channels. Washington: Pew Hispanic Center, Nov. de 2003. Available at: < http://www.pewhispanic.org/files/reports/23.pdf $>$. Accessed on: 15 oct. 2015.

REVELEZ, Lincoln Bizzozero. La educación superior en el Sector Educativo del Mercosur: impactos en la migración intrarregional y perspectivas en el proceso de integración. In: LAS MIGRACIONES humanas en el Mercosur: una mirada desde los derechos humanos, compilación normativa. Montevideo: Observatório de Políticas Públicas de Derechos Humanos en el Mercosur, 2009. p. 35-46.

RODRIGUES, José Noronha. Cidadania e Direitos Fundamentais. Revista Direitos Fundamentais e Democracia, Curitiba, v. 8, n. 8, p. 181-212, jul./dez. 2010.

ROLLI, Claudia. Governo paulista pretende qualificar estrangeiros. Folha de São Paulo. São Paulo, 11 ago. 2013. Disponível em: <http://www1.folha.uol.com. br/mercado/2013/08/1324746-governo-paulista-pretende-qualificar-estrangeiros.shtml $>$. Acesso em: 10 out. 2013.

SALZMANN, Antonio Cardesa. El contenido jurídico de la libre circulación de personas en el Mercosur: balance y perspectivas. In: GOIZUETA VÉRTIZ, Juana; GÓMEZ FERNÁNDEZ, Itziar; PASCUAL GONZÁLEZ, María Isabel. La libre círculación de personas en los sistemas de integración económica: modelos comparados: Unión Europea, Mercosur y Comunidad Andina. Navarra: Thomson Reuters Aranzadi, 2012. p. 163-185.

SANT'ANA, Marcílio Ribeiro de. A livre circulação de trabalhadores no Mercosul. In: Brasil, migracōes internacionais e identidade. 2000. Disponível em: <http://www. comciencia.br/reportagens/migracoes/migr08.htm>. Acesso em: 23 nov. 2014.

TRATADO que institui a Comunidade Económica Europeia ou Tratado CEE - texto original (versão não consolidada). Disponível em: <http://eur-lex.europa. eu/legal-content/PT/TXT/HTML/?uri=URISERV:x y0023\&from=PT $>$. Acesso em: 15 dez. 2015.

URIARTE, Ermida Oscar. La dimensión social del Mercosur. Montevideo: Fundación de Cultura Universitaria, 2004.

VALADÃO, Marcos Aurelio Pereira. Legal and institutional dimensions of reform: Washington Consen- 
sus and Latin America integration: Mercosur and the road to regional inconsistencies - to where are we going exactly?. Law and Business Review of the Americas, Dallas, v. 15, n. 1, p. 207-220, 2009.

VARELA, Justo Corti. Evolución de la libre circulación de personas en el Mercosur y su impacto en las políticas migratorias nacionales. In: GOIZUETA VÉRTIZ, Juana; GÓMEZ FERNÁNDEZ, Itziar; PASCUAL GONZÁLEZ, María Isabel. La libre círculación de personas en los sistemas de integración económica: modelos comparados: Unión Europea, Mercosur y Comunidad Andina. Navarra: Thomson Reuters Aranzadi, 2012. p. 104-118.

VÁZQUEZ: hay que llenar de ciudadanía al Mercosur palabras del Presidente de la República, Tabaré Vázquez, durante la Cumbre de Jefes de Estados del Mercosur en Asunción. Disponível em: <http://archivo.presidencia. gub.uy/_web/noticias/2005/06/2005062007.htm>. Acesso em: 20 dez. 2014.

WHITE, Robin Ca. Free movement, equal treatment, and Citizenship of the Union. International and Comparative Law Quarterly, Cambridge, v. 54, n. 4, p. 885-905, Oct. 2005.

WOLKMER, Antônio Carlos. Integração e direito comunitário latino-americano. In: PIMENTEL, Luiz Otávio (Org.). Mercosul no cenário internacional: direito e sociedade. Curitiba: Juruá, 1998. v. 1. p. 43-54. 
Para publicar na Revista de Direito Internacional, acesse o endereço eletrônico www.rdi.uniceub.br ou www.brazilianjournal.org.

Observe as normas de publicação, para facilitar e agilizar o trabalho de edição. 